OPEN ACCESS

Edited by:

Yuguo Yu,

Fudan University, China

Reviewed by:

Lianchun Yu,

Lanzhou University, China

Thomas Launey,

RIKEN Brain Science Institute (BSI),

Japan

*Correspondence:

Xile We

xilewei@tju.edu.cn

Received: 18 May 2017

Accepted: 18 August 2017

Published: 01 September 2017

Citation:

Yi G, Wang J, Wei X and Deng B (2017) Dendritic Properties Control Energy Efficiency of Action Potentials

in Cortical Pyramidal Cells.

Front. Cell. Neurosci. 11:265

doi: 10.3389/fncel.2017.00265

\section{Dendritic Properties Control Energy Efficiency of Action Potentials in Cortical Pyramidal Cells}

\author{
Guosheng Yi, Jiang Wang, Xile Wei * and Bin Deng \\ School of Electrical and Information Engineering, Tianjin University, Tianjin, China
}

Neural computation is performed by transforming input signals into sequences of action potentials (APs), which is metabolically expensive and limited by the energy available to the brain. The metabolic efficiency of single AP has important consequences for the computational power of the cell, which is determined by its biophysical properties and morphologies. Here we adopt biophysically-based two-compartment models to investigate how dendrites affect energy efficiency of APs in cortical pyramidal neurons. We measure the $\mathrm{Na}^{+}$entry during the spike and examine how it is efficiently used for generating AP depolarization. We show that increasing the proportion of dendritic area or coupling conductance between two chambers decreases $\mathrm{Na}^{+}$entry efficiency of somatic AP. Activating inward $\mathrm{Ca}^{2+}$ current in dendrites results in dendritic spike, which increases AP efficiency. Activating $\mathrm{Ca}^{2+}$-activated outward $\mathrm{K}^{+}$current in dendrites, however, decreases $\mathrm{Na}^{+}$entry efficiency. We demonstrate that the active and passive dendrites take effects by altering the overlap between $\mathrm{Na}^{+}$influx and internal current flowing from soma to dendrite. We explain a fundamental link between dendritic properties and AP efficiency, which is essential to interpret how neural computation consumes metabolic energy and how biophysics and morphologies contribute to such consumption.

Keywords: dendrite, action potential, two-compartment model, $\mathrm{Na}^{+}$entry, metabolic efficiency

\section{INTRODUCTION}

Cortical pyramidal cells have powerful abilities to process incoming signals, which are metabolically expensive. They adopt diverse patterns of APs to encode information and perform computation. This is a primary process that consumes energy within a pyramidal cell (Sengupta et al., 2010; Niven, 2016). The availability of energy supply in the brain not only limits the survival (Diaz et al., 2012), development (Schuchmann et al., 2005), cellular maintenance (Engl and Attwell, 2015), and evolution (Niven and Laughlin, 2008) of a neuron, which also constrains its computational power (Attwell and Laughlin, 2001; Attwell and Gibb, 2005; Alle et al., 2009; Sengupta et al., 2010; Yu et al., 2012; Niven, 2016). Importantly, energy efficiency plays a critical role in coding schemes and strategies of neural system, which can determine information rate, coding capacity, signal transfer manner and transmission reliability (Schreiber et al., 2002; Sengupta et al., 2013, 2014; Yu and Liu, 2014; Wang et al., 2015; Zhang et al., 2015; Niven, 2016; Yu et al., 2016). In particular, there are trade-offs between energy expenditure and information processing (Schreiber et al., 2002; Sengupta et al., 2013; Yu and Liu, 2014; Niven, 2016). Such special relationship between them can govern the numbers and types of signaling molecules, synapses and ion channels used by cells, which also strongly influences neuronal anatomy and physiology at different scales 
(Schreiber et al., 2002; Niven, 2016). Investigating how metabolic energy is efficiently used to generate APs in pyramidal cells is therefore essential for deeply understanding their computation. It is also significant for interpreting neural circuit functions and functional imaging signals related to metabolic mechanisms (Niven and Laughlin, 2008; Sengupta et al., 2010; Yu et al., 2012; Niven, 2016).

In cortical pyramidal cells, the AP is initiated in the axon initial segment (AIS; Stuart et al., 1997), which arises from the non-linear interaction between inward and outward currents (Prescott et al., 2008). Two common ions include $\mathrm{Na}^{+}$and $\mathrm{K}^{+}$. According to their concentration gradients, $\mathrm{Na}^{+}$flows into the cell and $\mathrm{K}^{+}$out of the cell. When membrane depolarization reaches a threshold level (i.e., AP threshold), inward $\mathrm{Na}^{+}$ current becomes self-sustaining and vast number of $\mathrm{Na}^{+}$ions flow into the cell. It effectively depolarizes membrane potential and results in the fast upstroke of AP. Strong depolarization activates $\mathrm{K}^{+}$current and lets $\mathrm{K}^{+}$ions exit the cell. The efflux of $\mathrm{K}^{+}$hyperpolarizes membrane potential, which generates the falling phase of AP. To re-establish ion gradients and maintain signaling, the $\mathrm{Na}^{+} / \mathrm{K}^{+}$pump extrudes $\mathrm{Na}^{+}$ions and imports $\mathrm{K}^{+}$ions during each AP (Kandel et al., 2012; Niven, 2016). This subcellular process is performed by consuming significant quantities of metabolic energy provided by the hydrolysis of ATP molecules (Hasenstaub et al., 2010; Sengupta et al., 2010; Howarth et al., 2012; Niven, 2016). The $\mathrm{Na}^{+} / \mathrm{K}^{+}$pump hydrolyses one ATP when it imports two $\mathrm{K}^{+}$ions to the cell and extrudes three $\mathrm{Na}^{+}$ions out of the cell.

The metabolic energy consumed by an AP is tightly related to the entry of $\mathrm{Na}^{+}$ions into the cell (Carter and Bean, 2009; Yu et al., 2012). If $\mathrm{Na}^{+}$influx is confined to the rising phase of the AP and $\mathrm{K}^{+}$efflux to its falling phase, there would be perfect energy efficiency. However, the kinetics of voltage-gated channels causes the overlap between $\mathrm{Na}^{+}$and $\mathrm{K}^{+}$currents (Crotty et al., 2006; Carter and Bean, 2009; Hasenstaub et al., 2010). Such overlap would merely result in an electrically neutral exchange of positive ions, which makes $\mathrm{Na}^{+}$influx less efficient in generating membrane depolarization, thus inflating energy cost. The complete separation of opposite currents decreases energy expenditure to close to the minimum possible, which increases $\mathrm{Na}^{+}$entry efficiency. The extent of the overlap between opposite currents determines the efficiency of both $\mathrm{Na}^{+}$entry and metabolic energy, which is highly variable among neurons. It is shown that channel types, densities and kinetics (Crotty et al., 2006; Crotty and Levy, 2007; Hasenstaub et al., 2010; Sengupta et al., 2010; Moujahid and d'Anjou, 2012; Yi et al., 2016a), AP shape (Carter and Bean, 2009), spike threshold dynamics (Yi et al., 2015a), and temperature (Moujahid and d'Anjou, 2012; Yu et al., 2012) could all influence $\mathrm{Na}^{+}$entry efficiency through altering the overlap of opposite currents. To interpret the energy cost in pyramidal cells, it is essential to understand the efficiency of $\mathrm{Na}^{+}$entry during an AP and its relationship with biophysical properties and morphology of the cell.

Dendrites are the primary sites for receiving signals in cortical pyramidal cells (Spruston, 2008), which also deliver them to the initiation zone of APs. Their tree-like structure disperses input sites and effectively extends the receptive field of the cell
(Spruston, 2008; Grienberger et al., 2015). Particularly, each dendritic branch is an independent processing and signaling unit (Branco and Häusser, 2010), which can perform local computation by integrating synaptic input. Such local integration is critically dependent on their passive and active properties (Spruston, 2008; Stuart and Spruston, 2015; Tran-Van-Minh et al., 2015). Specifically, the passive properties, such as axial resistance, diameter, branching, and the distance of the synapse from the soma, mainly filter and attenuate synaptic inputs as they spread to the soma, resulting in passive/sublinear integration (Stuart and Spruston, 2015; Tran-Van-Minh et al., 2015). The active currents can either boost or attenuate dendritic depolarization. Activating the active conductance of inward currents initiates dendritic spike. Such local thresholddependent regenerative response boosts inputs, resulting in active/supralinear integration (Major et al., 2013; Tran-VanMinh et al., 2015). On the contrary, activating outward $\mathrm{K}^{+}$ current produces sublinear integration (Hu et al., 2010; TranVan-Minh et al., 2015). The outcome of dendritic integration directly participates in AP initiation and alters the final output. Such non-linear transformation conferred by the dendrites can effectively increase the computational ability of pyramidal neurons (Spruston, 2008; Branco and Häusser, 2010; Major et al., 2013; Grienberger et al., 2015; Stuart and Spruston, 2015; Tran-Van-Minh et al., 2015). However, it is still unknown how dendrites influence the metabolic efficiency of somatic/axonal APs, leaving important questions unanswered. What roles do passive and active properties play in the efficiency of $\mathrm{Na}^{+}$entry? Do they affect AP efficiency also through altering the overlap of $\mathrm{Na}^{+}$and $\mathrm{K}^{+}$currents in the soma/axon? What properties of the dendrites are contributory factors for producing an energy efficient AP?

Here we attempt to answer these questions by numerical simulations of biophysically-based models. We develop three two-compartment models to describe passive and active dendrites. The excess $\mathrm{Na}^{+}$entry ratio (Carter and Bean, 2009; Yu et al., 2012) is applied to quantify how efficiently $\mathrm{Na}^{+}$influx is used for AP depolarization. By relating dendritic properties to the internal current flowing from the soma to the dendrite, and by identifying how such current overlaps with $\mathrm{Na}^{+}$influx in the soma, we explain how passive and active dendrites participate in the energy efficiency of APs in cortical pyramidal cells.

\section{METHODS}

The biophysically-based two-compartment models are used in our simulations. Such type of model is the minimal structure to capture the interactions between dendrites and soma/axon in cortical pyramidal cells. One chamber represents apical dendrites, and the other one describes the soma plus the AIS. APs are initiated and recorded in latter chamber. We develop three models to quantify how the passive and active properties of the dendrites affect the energy efficiency of APs.

\section{Model I}

Our starting model is derived from the Pinsky-Rinzel (PR) model (Pinsky and Rinzel, 1994). We block active currents in 
its dendritic chamber, and create a simple model with passive dendrite, i.e., model I. To generate APs, we include inward $\mathrm{Na}^{+}$ and outward $\mathrm{K}^{+}$currents in somatic chamber. The currentbalance equations for model I are described by

$$
\begin{aligned}
\mathrm{C}_{\mathrm{m}} \frac{\mathrm{d} V_{\mathrm{S}}}{\mathrm{d} t} & =-\frac{g_{\mathrm{c}}\left(V_{\mathrm{S}}-V_{\mathrm{D}}\right)}{p}-I_{\mathrm{Na}}-I_{\mathrm{K}}-I_{\mathrm{SL}} \\
\mathrm{C}_{\mathrm{m}} \frac{\mathrm{d} V_{\mathrm{D}}}{\mathrm{d} t} & =I_{\mathrm{D}}+\frac{g_{\mathrm{c}}\left(V_{\mathrm{S}}-V_{\mathrm{D}}\right)}{1-p}-I_{\mathrm{DL}}
\end{aligned}
$$

where $V_{\mathrm{S}}$ and $V_{\mathrm{D}}$ are the transmembrane potentials of soma and dendrite. $I_{\mathrm{D}}$ (in $\mu \mathrm{A} / \mathrm{cm}^{2}$ ) is the input current applied to activate neurons. $\mathrm{C}_{\mathrm{m}}=1 \mu \mathrm{F} / \mathrm{cm}^{2}$ is the membrane capacitance. $p$ and $1-p$ are two morphological parameters, which respectively describe the proportion of cell area taken up by the soma and the dendrite. Two compartments are separated by an internal coupling conductance $g_{\mathrm{c}}\left(\right.$ in $\left.\mathrm{mS} / \mathrm{cm}^{2}\right)$. $I_{\mathrm{SD}}=g_{\mathrm{c}}\left(V_{\mathrm{S}}-V_{\mathrm{D}}\right) / p$ is the internal current flowing from the soma to the dendrite along internal conductance. Other ionic currents included in model I are

$$
\begin{aligned}
I_{\mathrm{Na}} & =\overline{\mathrm{g}}_{\mathrm{Na}} m_{\infty}^{3}\left(V_{\mathrm{S}}\right) h\left(V_{\mathrm{S}}-\mathrm{E}_{\mathrm{Na}}\right) \\
I_{\mathrm{K}} & =\overline{\mathrm{g}}_{\mathrm{K}} n^{4}\left(V_{\mathrm{S}}-\mathrm{E}_{\mathrm{K}}\right) \\
I_{\mathrm{SL}} & =\mathrm{g}_{\mathrm{SL}}\left(V_{\mathrm{S}}-\mathrm{E}_{\mathrm{SL}}\right) \\
I_{\mathrm{DL}} & =\mathrm{g}_{\mathrm{DL}}\left(V_{\mathrm{D}}-\mathrm{E}_{\mathrm{DL}}\right)
\end{aligned}
$$

The gating variables, including activation and inactivation variables for inward $I_{\mathrm{Na}}$ (i.e., $m$ and $h$ ) and activation variable for outward $I_{\mathrm{K}}$ (i.e., $n$ ), satisfy following first-order kinetics

$$
\frac{\mathrm{d} x}{\mathrm{~d} t}=\alpha_{x}\left(V_{\mathrm{S}}\right)(1-x)-\beta_{x}\left(V_{\mathrm{S}}\right) x
$$

where $x \in\{m, h, n\}$. Here the details of each current follow the descriptions by Wang (1998). For each gating variable, the transition rate $\alpha_{x}$ and $\beta_{x}$ are

$$
\begin{aligned}
\alpha_{m} & =-0.1\left(V_{\mathrm{S}}+33\right) /\left\{\exp \left[-0.1\left(V_{\mathrm{S}}+33\right)\right]-1\right\} \\
\beta_{m} & =4 \exp \left[-\left(V_{\mathrm{S}}+58\right) / 12\right] \\
\alpha_{h} & =0.07 \exp \left[-\left(V_{\mathrm{S}}+50\right) / 10\right] \\
\beta_{h} & =1 /\left\{\exp \left[-0.1\left(V_{\mathrm{S}}+20\right)\right]+1\right\} \\
\alpha_{n} & =-0.01\left(V_{\mathrm{S}}+34\right) /\left\{\exp \left[-0.1\left(V_{\mathrm{S}}+34\right)\right]-1\right\} \\
\beta_{n} & =0.125 \exp \left[-\left(V_{\mathrm{S}}+44\right) / 25\right]
\end{aligned}
$$

In model $\mathrm{I}$, the activation variable $m$ of $I_{\mathrm{Na}}$ is replaced by its steady state $m_{\infty}=\alpha_{m} /\left(\alpha_{m}+\beta_{m}\right) \quad$ (Wang, 1998). $\overline{\mathrm{g}}_{\mathrm{Na}}=$ $45 \mathrm{mS} / \mathrm{cm}^{2}, \overline{\mathrm{g}}_{\mathrm{K}}=18 \mathrm{mS} / \mathrm{cm}^{2}, \mathrm{~g}_{\mathrm{SL}}=0.1 \mathrm{mS} / \mathrm{cm}^{2}$, and $\mathrm{g}_{\mathrm{DL}}=$ $0.1 \mathrm{mS} / \mathrm{cm}^{2}$ are the maximum conductances associated with the currents. $\mathrm{E}_{\mathrm{Na}}=55 \mathrm{mV}, \mathrm{E}_{\mathrm{K}}=-80 \mathrm{mV}, \mathrm{E}_{\mathrm{SL}}=-65 \mathrm{mV}$, and $\mathrm{E}_{\mathrm{DL}}=-65 \mathrm{mV}$ are the reversal potentials for relevant channels. This model is used to simulate the effects of varying morphological parameter $p$ and coupling conductance $g_{c}$ on the energy efficiency of APs, i.e., the passive properties of dendritic chamber.

\section{Model II}

To determine how active dendrites affect AP efficiency, we introduce an inward $\mathrm{Ca}^{2+}$ current $I_{\mathrm{Ca}}$ into the dendritic chamber of model I, and develop another two-compartment model, i.e., model II. The $\mathrm{Ca}^{2+}$ current is given by (Mainen and Sejnowski, 1996)

$$
I_{\mathrm{Ca}}=\overline{\mathrm{g}}_{\mathrm{Ca}} s^{2} c\left(V_{\mathrm{D}}-\mathrm{E}_{\mathrm{Ca}}\right)
$$

Here $\overline{\mathrm{g}}_{\mathrm{Ca}}=0.8 \mathrm{mS} / \mathrm{cm}^{2}$ and $\mathrm{E}_{\mathrm{Ca}}=140 \mathrm{mV}$, which are modified from the PR like models (Pinsky and Rinzel, 1994; Wang, 1998; Park et al., 2005). Kinetics of activation variable $s$ and inactivation variable $c$ obeys

$$
\begin{aligned}
& \frac{\mathrm{d} s}{\mathrm{~d} t}=\frac{s_{\infty}\left(V_{\mathrm{D}}\right)-s}{\tau_{s}\left(V_{\mathrm{D}}\right)}=\alpha_{s}\left(V_{\mathrm{D}}\right)(1-s)-\beta_{s}\left(V_{\mathrm{D}}\right) s \\
& \frac{\mathrm{d} c}{\mathrm{~d} t}=\frac{c_{\infty}\left(V_{\mathrm{D}}\right)-c}{\tau_{c}\left(V_{\mathrm{D}}\right)}=\alpha_{c}\left(V_{\mathrm{D}}\right)(1-c)-\beta_{c}\left(V_{\mathrm{D}}\right) c
\end{aligned}
$$

The transition rate for gating variable $s$ and $c$ are

$$
\begin{aligned}
\alpha_{s} & =0.005\left(V_{\mathrm{D}}+27\right) /\left\{1-\exp \left[-\left(27+V_{\mathrm{D}}\right) / 3.8\right]\right\} \\
\beta_{s} & =0.94 \exp \left[-\left(V_{\mathrm{D}}+75\right) / 17\right] \\
\alpha_{c} & =0.000457 \exp \left[-\left(V_{\mathrm{D}}+13\right) / 50\right] \\
\beta_{c} & =0.0065 /\left\{1+\exp \left[-\left(V_{\mathrm{D}}+15\right) / 28\right]\right\}
\end{aligned}
$$

The kinetics of gating variable $s$ and $c$ is the same as that described by Mainen and Sejnowski (1996). This model is used to examine how activating $\mathrm{Ca}^{2+}$ current in dendritic chamber affects AP efficiency.

\section{Model III}

By introducing an outward current $I_{\mathrm{KAHP}}$ into the active dendrite of model II, we derive model III. $I_{\mathrm{KAHP}}$ is a voltage-independent, $\mathrm{Ca}^{2+}$-activated $\mathrm{K}^{+}$current, and activating it causes spikefrequency adaptation (SFA) on slow timescales. This inhibitory current is described by (Pinsky and Rinzel, 1994; Park et al., 2005)

$$
I_{\mathrm{KAHP}}=\overline{\mathrm{g}}_{\mathrm{KAHP}} q\left(V_{\mathrm{D}}-\mathrm{E}_{\mathrm{K}}\right)
$$

Here the maximal conductance is $\overline{\mathrm{g}}_{\mathrm{KAHP}}=5 \mathrm{mS} / \mathrm{cm}^{2}$. Kinetics of activation variable $q$ is given by

$$
\frac{\mathrm{d} q}{\mathrm{~d} t}=\frac{q_{\infty}\left(V_{\mathrm{D}}\right)-q}{\tau_{q}}
$$

where time constant is $\tau_{q}=800 \mathrm{~ms}$, and steady-state function is $q_{\infty}=\alpha_{q} /\left(\alpha_{q}+\beta_{q}\right)$. The transition rates for $I_{\mathrm{KAHP}}$ are $\alpha_{q}=$ $\min (0.00002[\mathrm{Ca}], 0.01)$ and $\beta_{q}=0.001$. [Ca] is the intracellular $\mathrm{Ca}^{2+}$ concentration, and its kinetics follows

$$
\frac{\mathrm{d}[\mathrm{Ca}]}{\mathrm{d} t}=-0.13 I_{\mathrm{Ca}}-0.075[\mathrm{Ca}]
$$

This model is used to simulate the effects of activating hyperpolarizing current in dendritic chamber on AP efficiency. 
We apply excess $\mathrm{Na}^{+}$entry ratio to quantify the efficiency of $\mathrm{Na}^{+}$entry during an AP. Following Carter and Bean (2009), it is defined as the ratio of total actual $\mathrm{Na}^{+}$entry $\mathrm{Q}_{\text {total }}$ during the AP to the minimal $\mathrm{Na}^{+}$load $\mathrm{Q}_{\text {min }}$ necessary for producing the voltage change of the AP. For a spike train recorded in our simulations, an AP is required to begin and end below or closest to the resting potential and cross at least $0 \mathrm{mV}$ at maximum (Hasenstaub et al., 2010). In this case, all of the active ionic currents take place during the defined interval of the AP (Crotty et al., 2006). Total $\mathrm{Na}^{+}$load $\mathrm{Q}_{\text {total }}$ per spike is calculated by integrating the $\mathrm{Na}^{+}$current curve over the duration of the AP (Carter and Bean, 2009; Hasenstaub et al., 2010; Sengupta et al., 2010, 2013; Yu et al., 2012), i.e., $Q_{\text {total }}=\int I_{\mathrm{Na}}(t) \mathrm{d} t$. Minimum charge $\mathrm{Q}_{\min }$ necessary to produce the depolarization of the AP is calculated as $\mathrm{Q}_{\min }=\mathrm{C}_{\mathrm{m}} \Delta V_{\mathrm{S}}$, where $\mathrm{C}_{\mathrm{m}}$ is the membrane capacitance. As mentioned in Introduction, an AP is initiated when enough membrane depolarization accumulates to bring $V_{\mathrm{S}}$ to reach spike threshold. After that, inward $\mathrm{Na}^{+}$current becomes self-sustaining to result in a positive feedback loop and generate the rising phase of the AP. To calculate the minimum charge $\mathrm{Q}_{\min }$, we measure $\Delta V_{\mathrm{S}}$ as the change of somatic voltage from spike threshold $\left(\mathrm{d} V_{\mathrm{S}} / \mathrm{d} t=20 \mathrm{mV} / \mathrm{ms}\right)$ to the peak of the $\mathrm{AP}\left(\mathrm{d} V_{\mathrm{S}} / \mathrm{d} t=0 \mathrm{mV} / \mathrm{ms}\right)$ (Carter and Bean, 2009; Yu et al., 2012; Ju et al., 2016). The excess $\mathrm{Na}^{+}$entry ratio calculated in this way has been widely applied to describe the metabolic efficiency of the APs in different kinds of cells (Attwell and Laughlin, 2001; Alle et al., 2009; Carter and Bean, 2009; Sengupta et al., 2010; Moujahid and d'Anjou, 2012; Yu et al., 2012; Niven, 2016; Yi et al., 2016a). It is shown that a lower value means most of $\mathrm{Na}^{+}$entry is confined to the depolarizing phase of the spike, and there are less overlaps between inward and outward currents, corresponding to a relatively efficient AP. On the contrary, a higher value of $\mathrm{Na}^{+}$entry ratio indicates that more of metabolic energy is devoted to the reversal of ion exchanges, which corresponds to an inefficient AP. The temporal overlap of inward $I_{\mathrm{Na}}$ and outward $I_{\mathrm{K}}$ (i.e., Q Qverlap) is measured as the difference between the total $\mathrm{Na}^{+}$load during an AP and the associated depolarizing component of the $\mathrm{Na}^{+}$load (Crotty et al., 2006; Sengupta et al., 2010; Moujahid and d'Anjou, 2012).

Earlier studies (Crotty et al., 2006; Hasenstaub et al., 2010; Howarth et al., 2012; Sengupta et al., 2013) determine the energy cost of an AP by the amount of ATP molecules expended in the spike duration. It is known that the $\mathrm{Na}^{+} / \mathrm{K}^{+}$-ATPase hydrolyses one ATP per three $\mathrm{Na}^{+}$extruded and two $\mathrm{K}^{+}$imported. Based on this fact, they measure the amount of $\mathrm{Na}^{+}$(or $\mathrm{K}^{+}$) ions consumed in the AP. The total $\mathrm{Na}^{+}$(or $\mathrm{K}^{+}$) load is then converted to the number of ATP molecules by using the 3:1 (or 2:1) stoichiometry of the $\mathrm{Na}^{+} / \mathrm{K}^{+}$-ATPase. Thus, there is a direct relationship between total $\mathrm{Na}^{+}$load $\mathrm{Q}_{\text {total }}$ during an AP and its energy cost. Following Sengupta et al. (2010), we use $\mathrm{Q}_{\text {total }}$ to define the energy consumption of an AP in our simulations. Note that such definition of AP cost is not accurate, but it does not alter our predictions about how dendrites affect the metabolic efficiency of somatic APs.

The shape of the simulated APs is characterized by their height and half-width. The height is determined by measuring the difference in somatic voltage $V_{\mathrm{S}}$ from the peak to the most negative voltage reached after the AP (Carter and Bean, 2009; Sengupta et al., 2010; Yu et al., 2012). The half-width is measured as the spike width at half the AP height.

All simulations of the two-compartment models are performed in MATLAB environment. The aforementioned dynamical equations are integrated numerically by using ode23 solver, with a time resolution of $0.001 \mathrm{~ms}$. The computer code for model simulations in present study will be available for public download under the ModelDB section of the Senselab database (https://senselab.med.yale.edu/modeldb/enterCode. cshtml? model=230329).

\section{RESULTS}

\section{Increasing the Proportion of Dendritic Area Decreases $\mathrm{Na}^{+}$Entry Efficiency of APs}

Our first step is to examine the effects of passive properties of the dendrites. A simple two-compartment model is adopted to simulate APs generated in the soma of cortical pyramidal cells, i.e., model I (Figure 1A). There are no active currents in its dendritic chamber. This model includes a morphological parameter $p$ that describes the proportion of soma area, and we use it to characterize dendritic geometry. In our twocompartment models, increasing $p$ means there is a decrease in dendrite area. We apply constant input $I_{\mathrm{D}}$ to activate model I and simultaneously record APs generated in somatic chamber. As parameter $p$ varies, the spike trains are always periodic (Figure 1B), but the AP shape alters. Specifically, the height and half-width of the AP both increase with parameter $p$ (Figure 1C), i.e., decreases with dendrite area.

We adopt excess $\mathrm{Na}^{+}$entry ratio to quantify the metabolic efficiency of the recorded APs, and examine how dendrite area affects this quantity. It is shown that the total $\mathrm{Na}^{+}$load $\mathrm{Q}_{\text {total }}$ during an AP increases at first and then decreases with parameter $p$ (Figure 1D, top). This means that the metabolic cost per AP is low with large dendrite area, i.e., energy efficient. The APs with moderate size of dendritic chamber are metabolically inefficient, since they have high energy cost. Unlike $\mathrm{Q}_{\text {total }}$, the minimal $\mathrm{Na}^{+}$load $\mathrm{Q}_{\text {min }}$ needed to generate the upstroke of the AP increases monotonically in the observed range of $p$ (Figure 1D, bottom). By calculating $\mathrm{Q}_{\text {total }} / \mathrm{Q}_{\min }$, we find that the excess $\mathrm{Na}^{+}$entry ratio decreases with parameter $p$ (Figure 1E). That is, increasing dendrite area in model I neuron increases its $\mathrm{Na}^{+}$entry ratio and facilitates to reduce AP efficiency. With large dendrite area (i.e., small $p$ ), the high $\mathrm{Na}^{+}$entry ratio shows that $\mathrm{Na}^{+}$influx is inefficiently used for the depolarization of relevant AP. Here more of the $\mathrm{Na}^{+}$influx during an AP is devoted to the reversal of ion exchanges. These simulations indicate that a small $\mathrm{Na}^{+}$entry ratio does not correspond to low energy cost for individual spikes. The metabolically efficient APs with large dendritic chamber may arise from other factors. We also calculate the temporal overlap Q Qverlap between $\mathrm{Na}^{+}$and $\mathrm{K}^{+}$currents during the repolarizing component of the $\mathrm{AP}$, which has been shown to be a determinant of metabolic efficiency. Unfortunately, we fail to identify a relationship between overlap load and $\mathrm{Na}^{+}$entry 
A model I: blocking active currents in dendritic chamber and varying $\mathrm{p}$
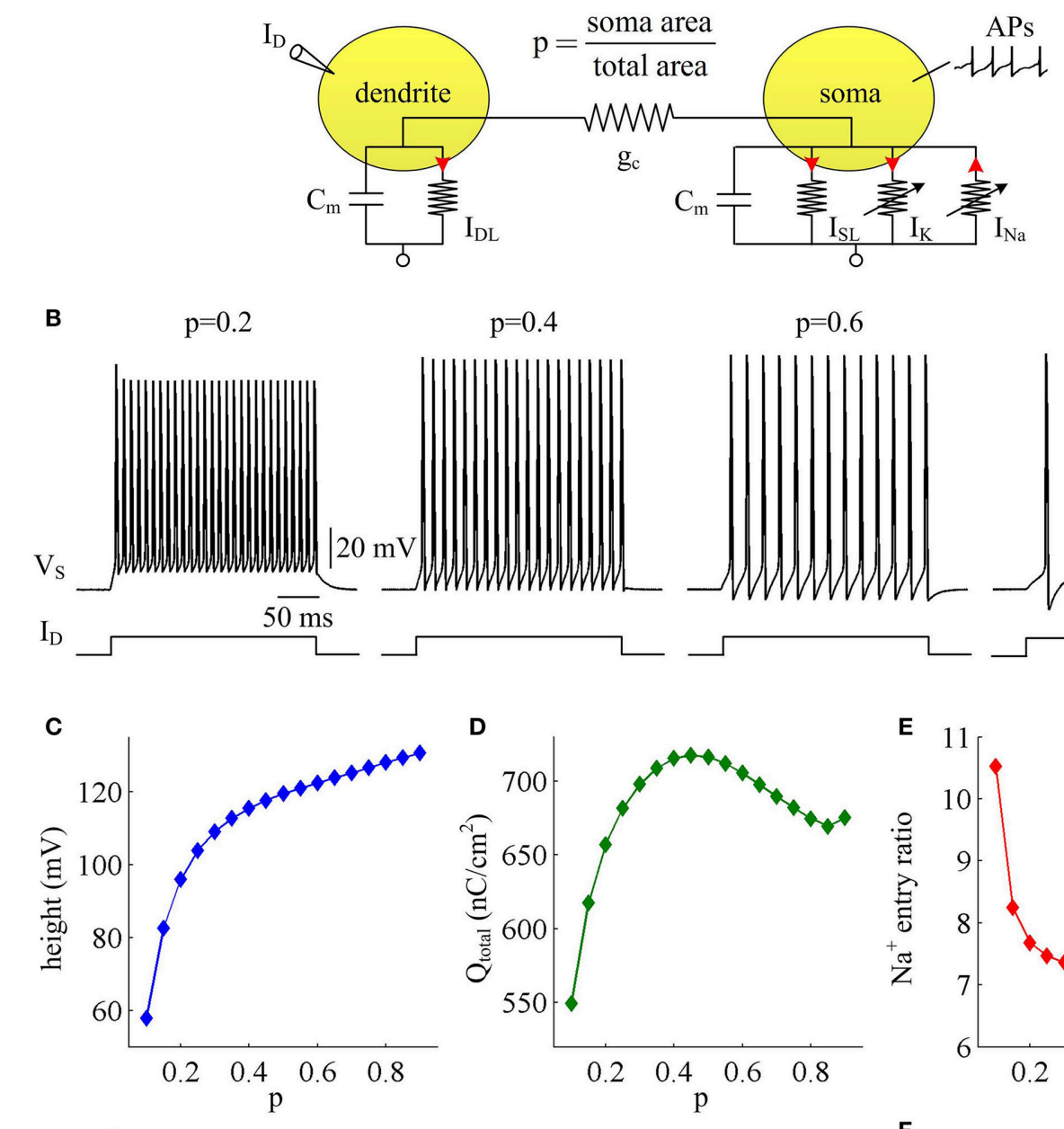

$\mathrm{p}=0.4$
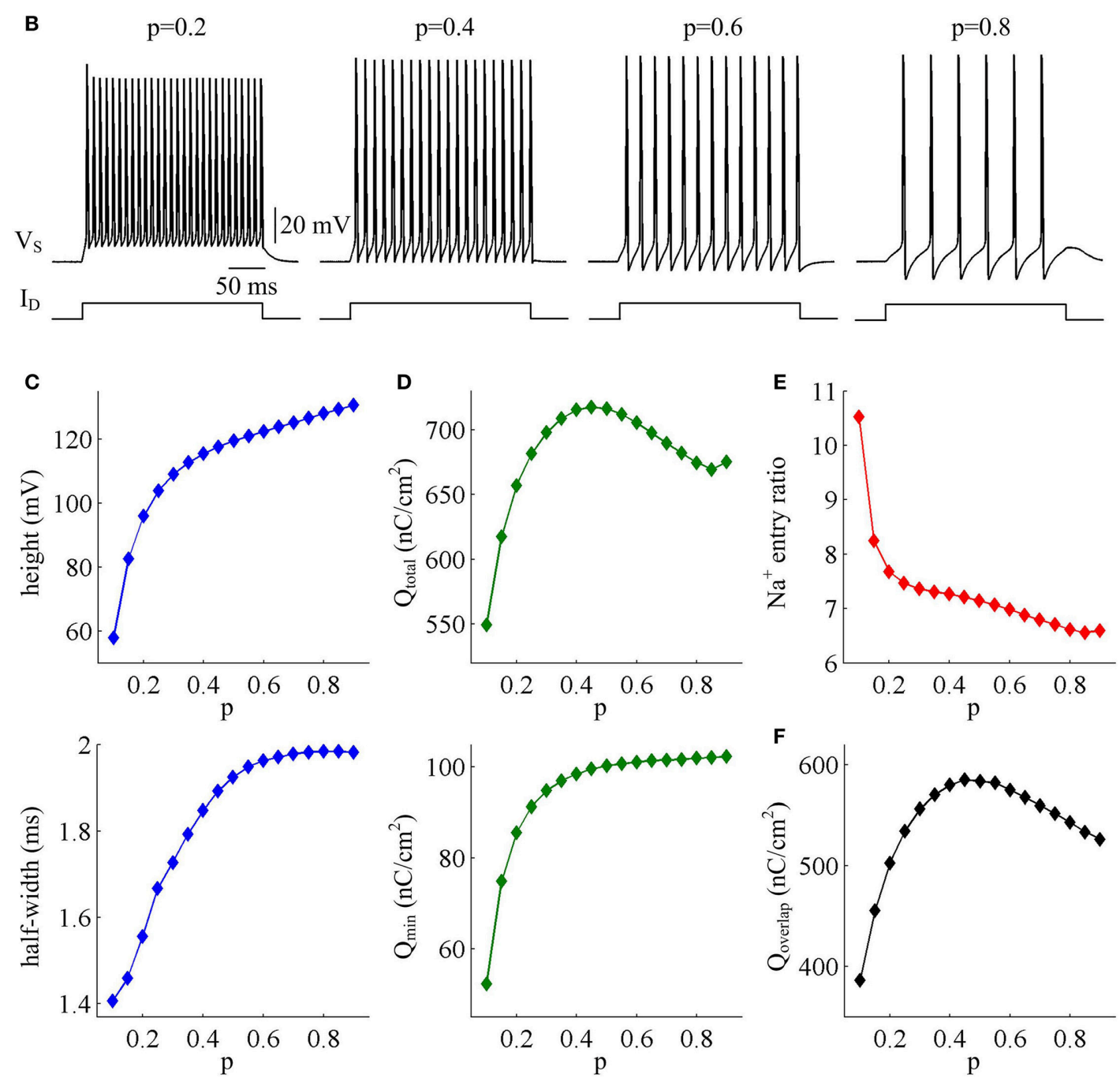

FIGURE 1 | AP shape and metabolic efficiency vary with dendrite area in model I. (A) Schematic of model I. There are no active channels in its dendritic chamber. Red arrows indicate the direction of ionic current. We set coupling conductance to $g_{c}=0.5 \mathrm{mS} / \mathrm{cm}^{2}$ and vary morphological parameter $p$. (B) Responses of membrane voltage $V_{\mathrm{S}}$ recorded from the soma with different values of $p$, which are indicated on the top of each panel. (C) Both height and half-width of the AP increase as a function of $p$. (D) Top panel: total $\mathrm{Na}^{+}$load $Q_{\text {total }}$ during an AP is plotted as a function of $p$. Note that $Q_{\text {total }}$ reaches a maximum with moderate value of $p$. Bottom panel: minimal $\mathrm{Na}^{+}$load $Q_{\text {min }}$ increases as a function of $p$. (E) $\mathrm{Na}^{+}$entry ratio decreases as a function of $p$. (F) Overlap $\mathrm{Na}^{+}$load $Q_{\mathrm{Overlap}}$ during an $\mathrm{AP}$ is plotted as a function of $p$. Similar to $Q_{\text {total }}, Q_{\text {overlap }}$ also reaches a maximum with moderate value of $p$. Dendritic input is $/ D=3 \mu A / \mathrm{cm}^{2}$.

ratio. We find that the overlap of inward $\mathrm{Na}^{+}$and outward $\mathrm{K}^{+}$currents during an AP reaches a maximum with moderate values of $p$ (Figure 1F). Therefore, we predict that increasing dendrite area may alter other outward currents to overlap with
$\mathrm{Na}^{+}$influx during the APs to result in inefficient use of $\mathrm{Na}^{+}$ entry.

To determine how dendrite area affects AP efficiency, we examine the ionic currents underlying the recorded APs in model 
I neuron. With low morphological parameter $p$, the soma is much smaller than the dendrite. Accordingly, the intensities of $I_{\mathrm{Na}}$ and $I_{\mathrm{K}}$ are both relatively weak during an individual spike (Figure 2A, $p=0.1$ ). This results in the APs with small height and short half-width (Figures 1B,C), which effectively decreases the metabolic cost of relevant AP. In this case, the small shape of the AP is the primary factor for its high energy efficiency. As parameter $p$ gets larger, soma area is increased, which reduces the constraint on ionic channels used for signaling. Then, the activation level of active currents gets higher, especially for inward $I_{\mathrm{Na}}$. This effectively increases AP size and relevant total $\mathrm{Na}^{+}$load, thus increasing its metabolic cost. Once $p$ exceeds 0.5 , the soma dominates cell excitability, and there are little changes in either $I_{\mathrm{Na}}$ or $I_{\mathrm{K}}$. Unlike two active channels, the internal current $I_{\mathrm{SD}}$ flowing out of the soma shows a marked decrease within the whole range of $p$ (Figure $2 \mathbf{A}$, bottom). The presence of outward $I_{\mathrm{SD}}$ results in an overlap between with $\mathrm{Na}^{+}$influx during the depolarizing phase of the AP. Such temporal overlap is in effect similar to the overlap between $I_{\mathrm{Na}}$ and $I_{\mathrm{K}}$ during the falling phase, which increases total $\mathrm{Na}^{+}$charge required for membrane depolarization. Decreasing the intensity of such inhibitory current effectively reduces $\mathrm{Na}^{+}$load. That is why total $\mathrm{Na}^{+}$load during an AP shows slight decrease once $p$ exceeds 0.5 . With high values of $p$, there is less outward current prior to AP initiation (Figure 2B, top), and inward $\mathrm{Na}^{+}$faces less competition as it depolarizes membrane potential $V_{\mathrm{S}}$. Then, $I_{\mathrm{Na}}$ is able to become self-sustaining at a more hyperpolarized voltage (Figure 2B, bottom), and results in a lower AP threshold (Figures 2C,D). Combined with increased AP peak, the minimal $\mathrm{Na}^{+}$load needed to produce the voltage change of the spike increases with parameter $p$. Further, the overlap between $\mathrm{Na}^{+}$ influx and outward $I_{\mathrm{SD}}$ during the depolarizing phase of an AP decreases as $p$ is increased. This makes APs become more effective to use $\mathrm{Na}^{+}$influx to achieve its depolarization, which results in a lower excess $\mathrm{Na}^{+}$entry ratio. These simulations indicate that increasing dendrite area increases the outward level of internal current $I_{\mathrm{SD}}$, which results in significant overlap between with $\mathrm{Na}^{+}$influx and then decreases the efficiency of $\mathrm{Na}^{+}$entry during an AP.

\section{Increasing Coupling Conductance between Two Compartments Decreases AP Efficiency}

Coupling conductance $g_{c}$ between two compartments is another passive property that controls internal current $I_{\mathrm{SD}}$ in twocompartment model. In this section, we adopt model I to simulate the effects of varying $g_{c}$ on the metabolic efficiency of APs (Figure 3A). In the observed range of $g_{c}$, model I neuron generates periodic spike trains to constant input $I_{\mathrm{D}}$ (Figure 3B). The AP shape shows similar evolutions with $g_{c}$ for different values of $p$ (Figures 3C,D). Note that the height and half-width of the AP is almost independent of the coupling conductance $g_{\mathrm{c}}$ with small dendrite area, such as $p=0.8$. In this case, the soma is much larger than the passive dendrite and dominates the output APs of model I. Thus, increasing $g_{c}$ connecting two chambers has little effects on AP shape.
Figure 4 shows the total $\mathrm{Na}^{+}$load, the minimal $\mathrm{Na}^{+}$load, the overlap load between $\mathrm{Na}^{+}$and $\mathrm{K}^{+}$currents, and the $\mathrm{Na}^{+}$ entry ratio during an $\mathrm{AP}$ as $g_{\mathrm{c}}$ varies. With different values of $p$, these items show similar trends in the observed range of $g_{c}$. As coupling conductance increases, the total $\mathrm{Na}^{+}$load during an AP is increased (Figure 4A) while the minimal $\mathrm{Na}^{+}$load is reduced (Figure 4B). Their ratio, i.e., excess $\mathrm{Na}^{+}$entry ratio, is monotonically increased with $g_{c}$ (Figure 4D), and relevant AP becomes less efficient to use $\mathrm{Na}^{+}$influx. This indicates that the generation of individual spike requires more energy and becomes metabolically inefficient with high coupling conductance. Once $g_{c}$ exceeds $2 \mathrm{mS} / \mathrm{cm}^{2}$, total $\mathrm{Na}^{+}$load, minimal $\mathrm{Na}^{+}$load and $\mathrm{Na}^{+}$entry ratio during an AP all show slight changes as $g_{\mathrm{c}}$ increases. Similar to parameter $p$, there is no obvious relationship between $\mathrm{Q}_{\text {overlap }}$ and $\mathrm{Na}^{+}$entry ratio (Figures $4 \mathrm{C}, \mathrm{D}$ ). Thus, the modulations of AP efficiency with coupling conductance $g_{\mathrm{c}}$ is not through altering the overlap load between $\mathrm{Na}^{+}$and $\mathrm{K}^{+}$currents during the repolarizing phase of APs. It is worth noting that the passive dendrite with large values of $p$ is so small that increasing $g_{c}$ has little effects on somatic APs and their underlying currents. Then, four items for relevant APs show little changes with coupling conductance (Figure $4, p=0.8$ ).

The simulations of varying dendrite area may lead one to hypothesize that it is the increase of outward current $I_{\mathrm{SD}}$ that is the primary effect in the increase of $\mathrm{Na}^{+}$entry ratio with each AP at higher coupling conductance. To test this hypothesis, we depict $I_{\mathrm{Na}}, I_{\mathrm{K}}$, and $I_{\mathrm{SD}}$ associated with the APs. It is shown that $I_{\mathrm{Na}}$ and $I_{\mathrm{K}}$ both change slightly as coupling conductance $g_{\mathrm{c}}$ varies (Figure 5A, center). However, internal current $I_{\mathrm{SD}}$ becomes progressively more prominent with $g_{c}$ (Figure 5A, bottom), especially during the rising phase of the spike. The presence of such inhibitory current at the subthreshold potentials antagonizes inward $\mathrm{Na}^{+}$current and makes it become selfsustaining at a more depolarized voltage (Figure 5B), which results in a higher AP threshold (Figure 5C). Combined with falling AP peak, the minimal $\mathrm{Na}^{+}$load needed to produce the upstroke of AP decreases with $g_{c}$. Further, the presence of outward $I_{\mathrm{SD}}$ during the depolarizing phase of AP leads to the overlap between with $\mathrm{Na}^{+}$influx. Under this condition, model I neuron has to import more $\mathrm{Na}^{+}$ions to compete with $I_{\mathrm{SD}}$ and generate the fast upstroke of APs. Then, the total $\mathrm{Na}^{+}$load during an $\mathrm{AP}$ is increased and corresponding $\mathrm{Na}^{+}$entry ratio gets larger. Therefore, the increase in excess $\mathrm{Na}^{+}$entry induced by increasing coupling conductance is largely owing to the increased overlap between outward $I_{\mathrm{SD}}$ and $\mathrm{Na}^{+}$influx during the depolarizing phase of the AP.

\section{Activating Inward $\mathrm{Ca}^{2+}$ Current in Dendrites Increases AP Efficiency}

With a simple two-compartment model, we have simulated how the passive properties of the dendrite modulate the energy efficiency of APs. Our next step is to examine the effects of active currents in dendrites. To achieve this goal, we introduce a voltage-dependent $\mathrm{Ca}^{2+}$ current $I_{\mathrm{Ca}}$ to the passive dendrite of model I and create model II (Figure 6A). Constant input $I_{\mathrm{D}}$ is applied to activate slow $I_{\mathrm{Ca}}$ and trigger APs. Activating active 


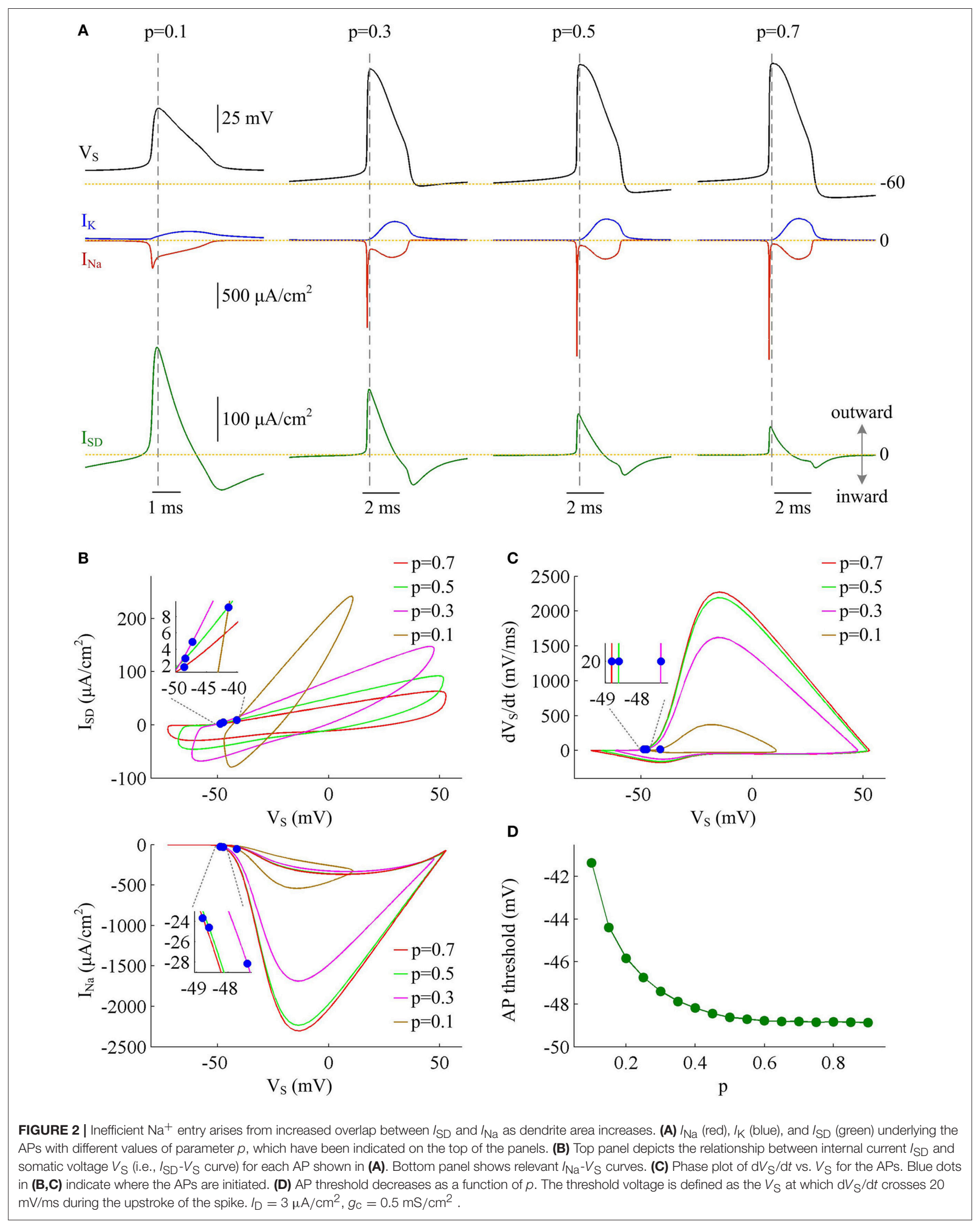


A

model I: blocking active currents in dendritic chamber and varying $\mathrm{g}_{\mathrm{c}}$
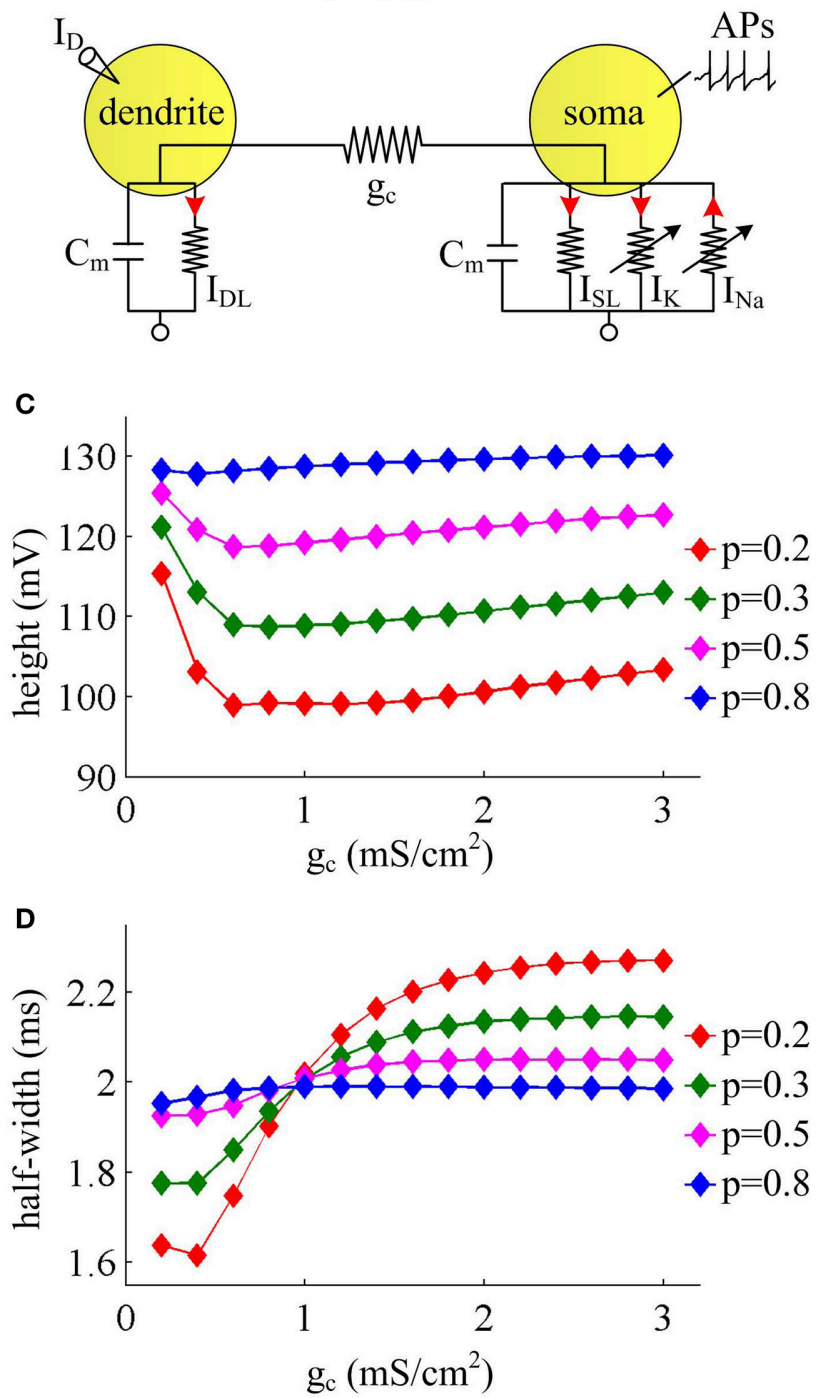

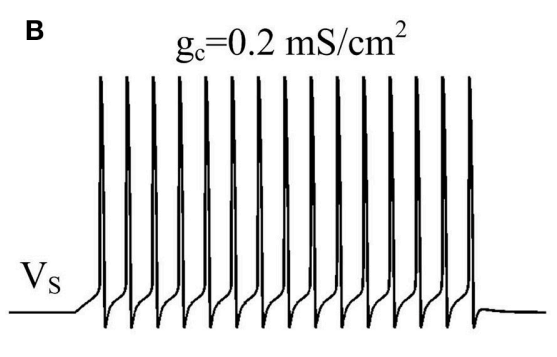

$\mathrm{g}_{\mathrm{c}}=0.8 \mathrm{mS} / \mathrm{cm}^{2}$

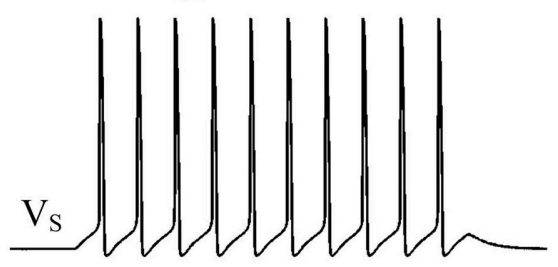

$\mathrm{g}_{\mathrm{c}}=1.6 \mathrm{mS} / \mathrm{cm}^{2}$

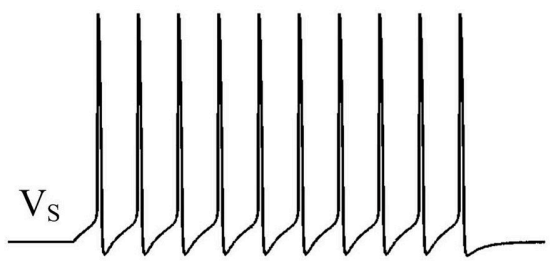

$\mathrm{g}_{\mathrm{c}}=2.4 \mathrm{mS} / \mathrm{cm}^{2}$

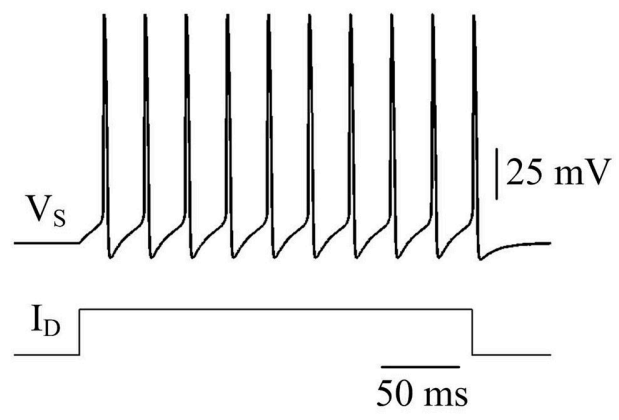

FIGURE 3 | AP shape varies with coupling conductance between chambers in model I. (A) We vary coupling conductance $g_{\mathrm{c}}$ in model I with passive dendrite. (B) Sample responses recorded in the soma with different values of $g_{\mathrm{C}}$, which are indicated on the top of each panel. Data are shown for $p=0.5$. (C) The height of the AP is plotted as a function of $g_{\mathrm{c}}$ for different values of $p$, which are $0.2,0.3,0.5$, and 0.8 . (D) The half-width of the AP is plotted as a function of $g_{\mathrm{c}}$ for each value of $p$. Dendritic input is $I_{D}=2 \mu \mathrm{A} / \mathrm{cm}^{2}$. Note that the height and half-width for individual spike in (C,D) are different from those with same values of $p$ and $g_{\mathrm{C}}$ in

Figure 1C. This arises from that stimulus input $I_{D}$ used in the case of varying dendrite area is $3 \mu \mathrm{A} / \mathrm{cm}^{2}$. Such higher current injection directly controls the excitability of two-compartment models and alters the shape of output APs.

$\mathrm{Ca}^{2+}$ channel results in a regenerative response in dendritic chamber (Figure 6B), which is referred to as dendritic $\mathrm{Ca}^{2+}$ spike. Such all-or-none event in dendritic chamber leads the neuron to generate a burst of high-frequency APs at the onset of input $I_{\mathrm{D}}$. In this case, the spike train recorded in somatic chamber is no longer periodic (Figure 6B, top). Meanwhile the AP shape also varies as $I_{\mathrm{Ca}}$ is activated. In particular, the height and half-width of the AP both decrease at first and then increase during the course of dendritic spike (Figures 6C,D). Increasing dendrite area extends $\mathrm{Ca}^{2+}$ spike and increases the intensity of internal current $I_{\mathrm{SD}}$, thus effectively enhancing the modulations of somatic APs.

We use $\mathrm{Na}^{+}$entry ratio to quantify the metabolic efficiency of the APs associated with dendritic $\mathrm{Ca}^{2+}$ spike. It is found that the total $\mathrm{Na}^{+}$load (Figure 7A) and the minimal $\mathrm{Na}^{+}$ load (Figure 7B) during each AP show similar trends as $I_{\mathrm{Ca}}$ is activated. Two items both decay down before $I_{\mathrm{Ca}}$ reaches its peak value and then increase in the second phase of dendritic spike. That is, the metabolic cost per spike is significantly reduced by the activation of inward $I_{\mathrm{Ca}}$. Interestingly, $\mathrm{Na}^{+}$entry ratio also 

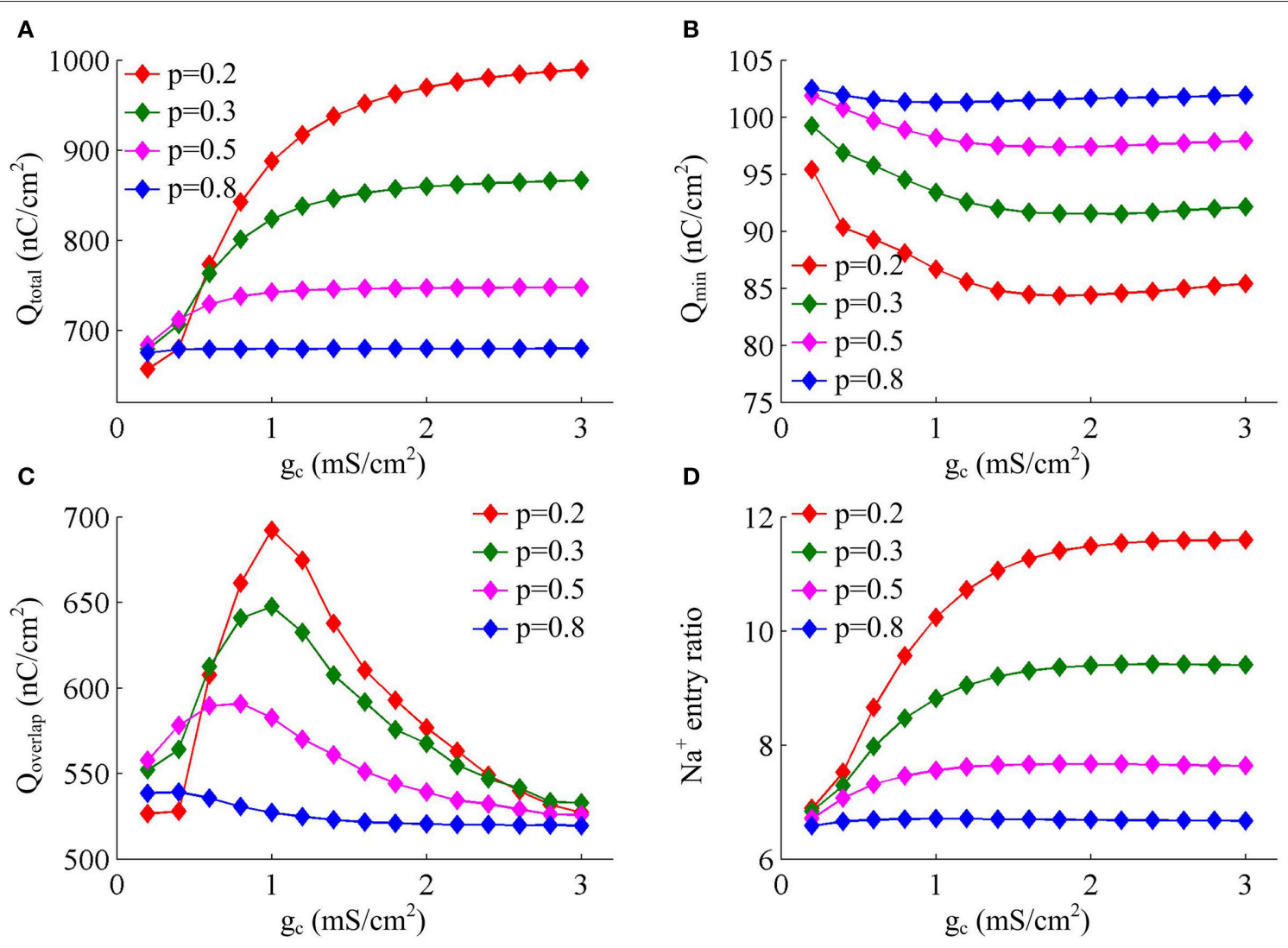

FIGURE 4 | Increasing coupling conductance between chambers reduces AP efficiency in model I. (A) Total $\mathrm{Na}^{+}$load $\mathrm{Q}_{\text {total }}$, (B) minimal Na+ load $\mathrm{Q}_{\text {min }}$, (C) overlap

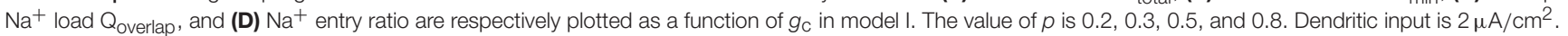
Since applied $I_{D}$ alters the final output of model I neuron, the items for an AP examined here are different from those with same $p$ and $g_{C}$ in Figures $\mathbf{1 D - F}$.

first quickly decreases to a minimal value and then slowly rises to a lower plateau level (Figure 7C). It is indicated that dendritic $\mathrm{Ca}^{2+}$ spike makes APs become more efficient to use $\mathrm{Na}^{+}$influx to generate their depolarization, thus increasing their metabolic efficiency.

Plots of $I_{\mathrm{Na}}, I_{\mathrm{K}}, I_{\mathrm{SD}}$, and $I_{\mathrm{Ca}}$ underlying individual spikes reveal that the efficient APs triggered by dendritic $\mathrm{Ca}^{2+}$ spike are also owing to the modulation of internal current $I_{\mathrm{SD}}$ (Figure 8). Specifically, once $V_{\mathrm{D}}$ is forced to reach a threshold voltage, slow inward $I_{\mathrm{Ca}}$ is activated and then a broader $\mathrm{Ca}^{2+}$ spike is initiated in dendritic chamber. Such regenerative event at the slow timescale results in a prolonged local depolarization of $V_{\mathrm{D}}$, which effectively decreases the outward level of $I_{\mathrm{SD}}$ and even switches its direction from outward to inward (Figures 6B, 8B). When $I_{\mathrm{SD}}$ still flows out of the soma, such as in the last phase of dendritic spike, decreasing its intensity reduces its overlap with $\mathrm{Na}^{+}$influx, thus increasing AP efficiency. When $I_{\mathrm{SD}}$ flows into the soma, the overlap between it and $\mathrm{Na}^{+}$influx during the upstroke of the AP disappears. Instead, the inward $I_{\mathrm{SD}}$ cooperates with $\mathrm{Na}^{+}$influx to contribute to the depolarization of somatic membrane, thus effectively increasing the efficiency of $\mathrm{Na}^{+}$entry. Meanwhile, the depolarizing $I_{\mathrm{SD}}$ induced by the activation of $I_{\mathrm{Ca}}$ also significantly reduces the intensity of $I_{\mathrm{Na}}$ and $I_{\mathrm{K}}$, especially the former (Figure $\mathbf{8 B}$, center). Under this condition, the height of relevant $\mathrm{AP}$ is reduced (Figure 6C) and its half-width gets narrow (Figure 6D). Then, the total $\mathrm{Na}^{+}$load per spike is significantly reduced during dendritic $\mathrm{Ca}^{2+}$ spike. As a result, activating $I_{\mathrm{Ca}}$ in the dendrite of model II neuron reduces the energy cost of somatic APs and makes them metabolically efficient.

\section{Activating Outward $\mathrm{Ca}^{2+}$-Activated $\mathrm{K}^{+}$ Current in Dendrites Decreases AP Efficiency}

Apart from inward active currents, there are also active currents flowing out of the dendrites, which mainly hyperpolarize dendritic membrane voltage. To determine how these inhibitory currents affect AP efficiency, we introduce a $\mathrm{Ca}^{2+}$-activated $\mathrm{K}^{+}$current $I_{\mathrm{KAHP}}$ into the dendritic chamber of model II and create model III (Figure 9A). The activation of $I_{\text {KAHP }}$ occurs at a slower timescale than the fast dynamics of APs, which includes a form of negative feedback to cell excitability. Here, we examine the $\mathrm{Na}^{+}$entry efficiency of the simulated APs as $I_{\mathrm{KAHP}}$ is activated.

Similar to above simulations, a constant input $I_{\mathrm{D}}$ is applied to activate $I_{\mathrm{KAHP}}$ and evoke APs. We find that the activation of $I_{\mathrm{KAHP}}$ in dendritic chamber reduces the firing rate to a lower steady-state level (Figure 9B, top), i.e., SFA occurs. During 


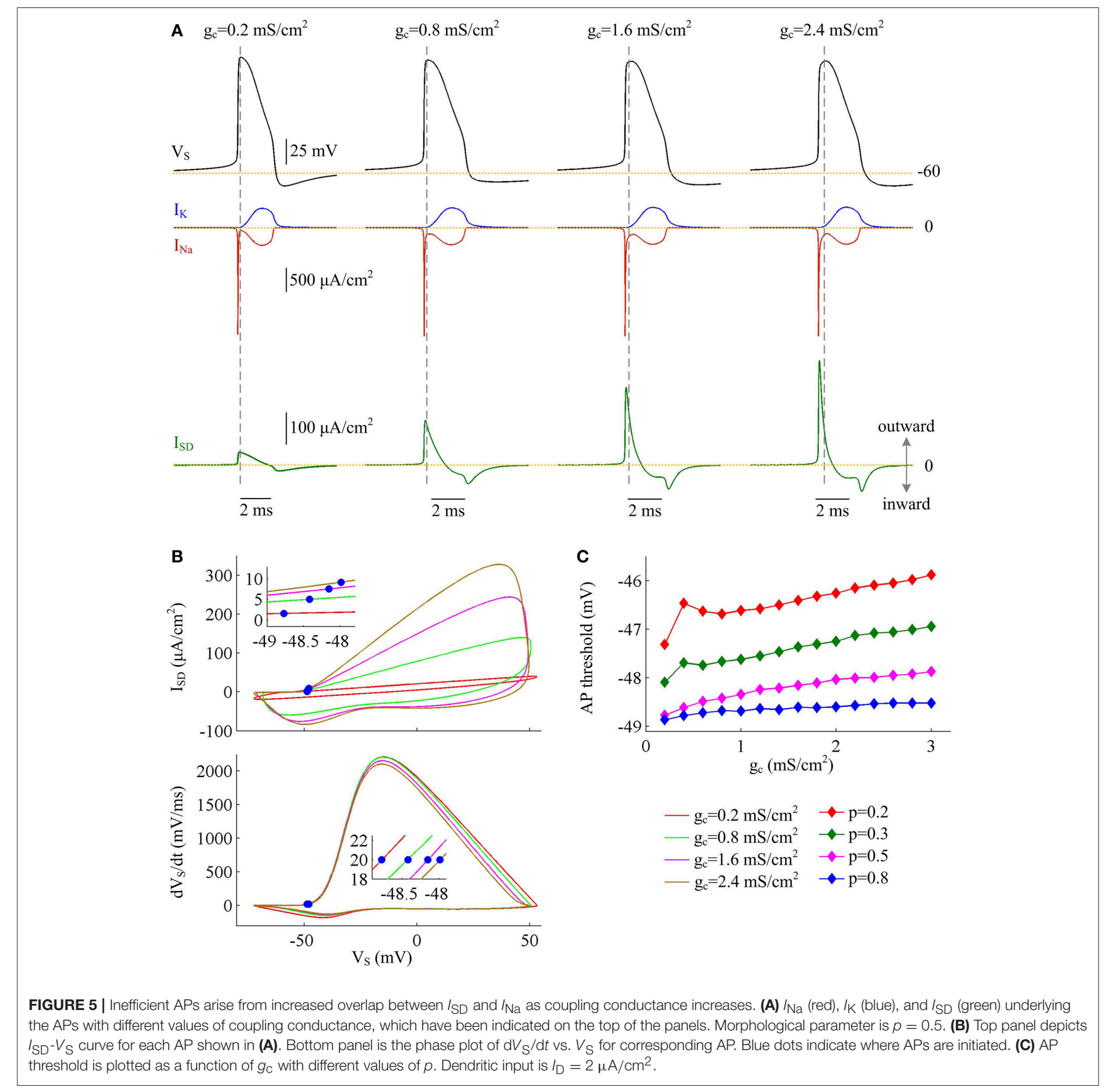

the course of SFA, $I_{\text {KAHP }}$ increases with co-occurring APs (Figure 9B, center). Once it is sufficiently activated, the firing rate no longer decreases and reaches a steady state. Increasing dendrite area produces little effects on the peak of $I_{\mathrm{KAHP}}$, whereas it increases the intensity of this current at the subthreshold voltages. Such manipulation also increases the amplitude of internal current $I_{\mathrm{SD}}$. In this case, activating $I_{\mathrm{KAHP}}$ with small dendritic chamber has less effect on the shape of somatic APs (Figures 9C,D). Unlike $I_{\mathrm{SD}}$, increasing dendrite area reduces the intensity of inward $I_{\mathrm{Ca}}$, which competes with outward $I_{\mathrm{KAHP}}$ in dendritic chamber to result in distinct modulations of AP shape. In particular, the AP half-width shows opposite evolutions with the activation of $I_{\mathrm{KAHP}}$ at different values of $p$ (Figure 9D). Further, there is a marked decrease in AP shape between the first two APs with $p=0.4$. This is because outward $I_{\mathrm{KAHP}}$ is close to $0 \mu \mathrm{A} / \mathrm{cm}^{2}$ during the first AP, which begins to take effects in the second $\mathrm{AP}$. In contrast, inward $I_{\mathrm{Ca}}$ is relatively strong in the first AP, and gradually decays as $I_{\mathrm{KAHP}}$ activates. The non-linear competition between $I_{\mathrm{KAHP}}$ and $I_{\mathrm{Ca}}$ leads to the marked decrease in AP height and half-width. 
A model II: introducing $\mathrm{I}_{\mathrm{Ca}}$ to the dendrite of model I to trigger dendritic $\mathrm{Ca}^{2+}$ spike
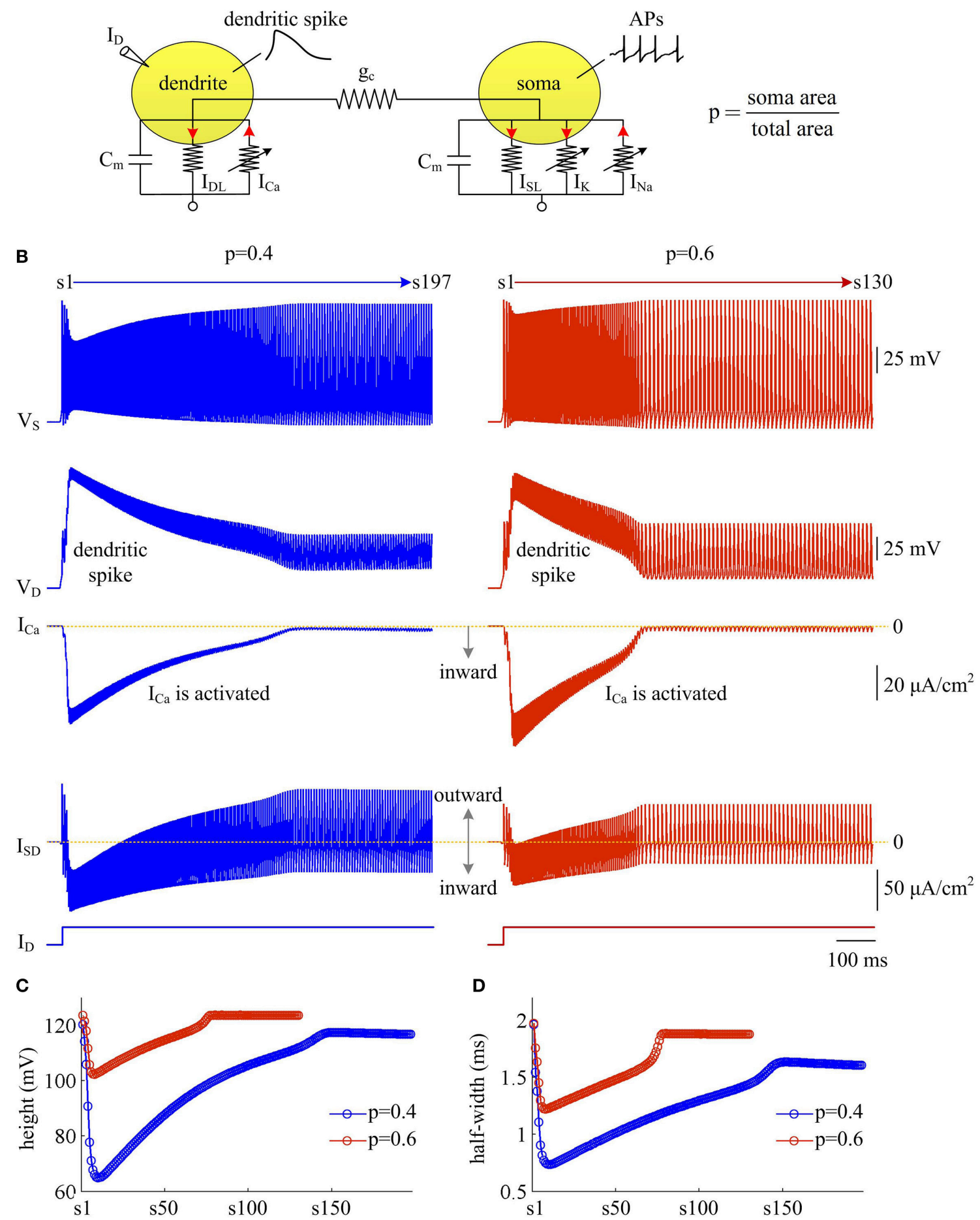

FIGURE 6 | Activating $\mathrm{Ca}^{2+}$ current in dendritic chamber results in dendritic spike in model II. (A) Schematic of model II. An inward Ca ${ }^{2+}$ current ICa is introduced to the dendritic chamber of model I. (B) Sample responses recorded in the soma with $p=0.4$ and 0.6 . Somatic voltage $V_{S}$, dendritic voltage $V_{\mathrm{D}}$, Ca ${ }^{2+}$ current $I_{\mathrm{Ca}}$ and internal current /SD are plotted against time. With $p=0.4$ (left), there are 197 APs generated during the interval of 1,000 ms, and we number them s1 through $\mathrm{s} 197$ from left to right. With $p=0.6$ (right), there are $130 \mathrm{APs}$ during the interval of 1,000 ms, and we number them s1 through $\mathrm{s} 130$ from left to right. (C) The height of each AP with $p=0.4$ and 0.6. (D) The half-width of each AP with $p=0.4$ and 0.6. Note that both height and half-width show marked decrease during the course of dendritic $\mathrm{Ca}^{2+}$ spike. $I_{\mathrm{D}}=5 \mu \mathrm{A} / \mathrm{cm}^{2}$ and $g_{\mathrm{C}}=0.3 \mathrm{mS} / \mathrm{cm}^{2}$. 

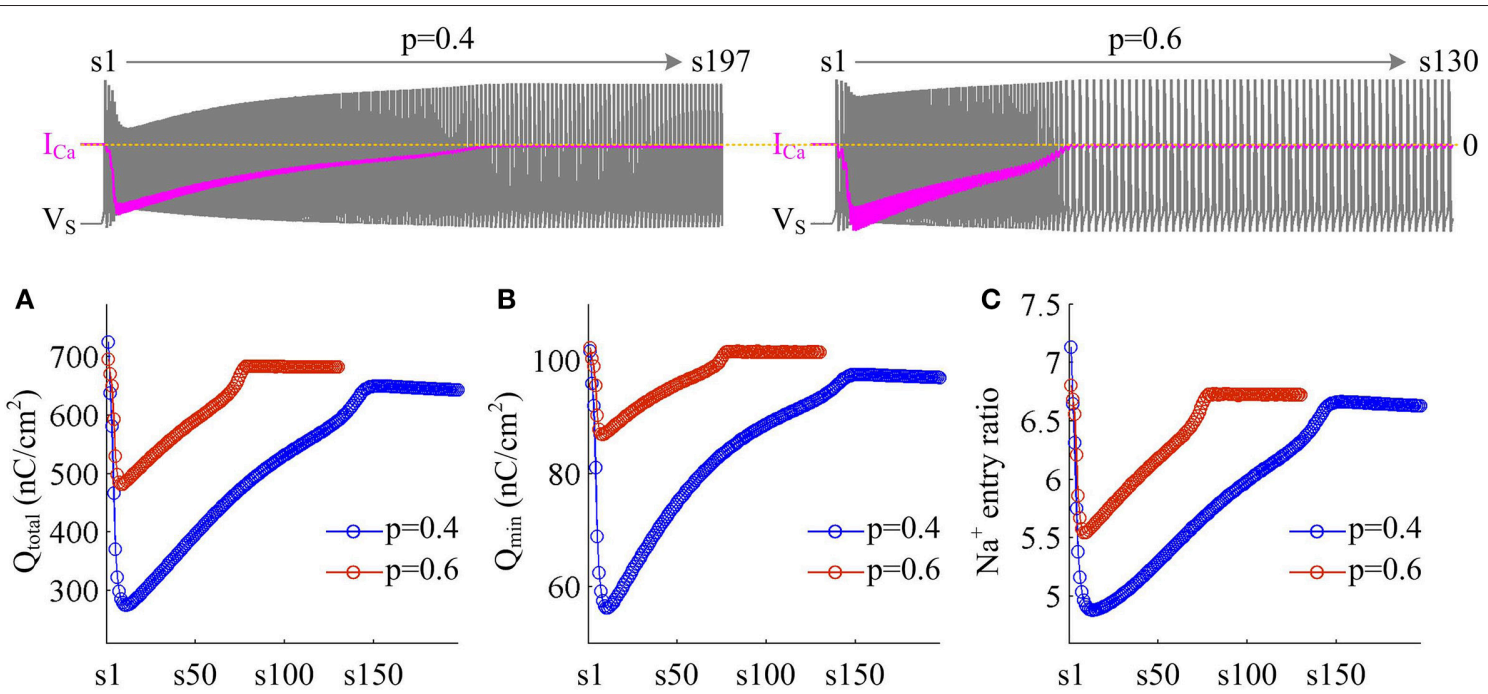

FIGURE 7 | Dendritic $\mathrm{Ca}^{2+}$ spike increases metabolic efficiency of APs. (A) Total $\mathrm{Na}^{+}$load $\mathrm{Q}_{\text {total, }}$ (B) minimal $\mathrm{Na}^{+}$load $\mathrm{Q}_{\mathrm{min}}$, and (C) $\mathrm{Na}^{+}$entry ratio are respectively computed for each $\mathrm{AP}$ during the activation of $I_{\mathrm{Ca}}$ with $p=0.4$ and 0.6 . Top panels show the response of $V_{\mathrm{S}}\left(\mathrm{gray}\right.$ ) and $I_{\mathrm{Ca}}$ (pink) recorded in the model $\mathrm{II}$ with each value of $p . I_{D}=5 \mu \mathrm{A} / \mathrm{cm}^{2}$ and $g_{c}=0.3 \mathrm{mS} / \mathrm{cm}^{2}$.

We measure the $\mathrm{Na}^{+}$entry ratio per AP during the time course of SFA. The results show that activating $I_{\mathrm{KAHP}}$ in dendritic chamber increases the total $\mathrm{Na}^{+}$load per spike (Figure 10A), thus increasing the metabolic cost of relevant AP. The minimal $\mathrm{Na}^{+}$load (Figure 10B) with different values of $p$ show opposite trends as $I_{\mathrm{Ca}}$ is activated. This arises from the interactions of $I_{\mathrm{KAHP}}$ with different intensities of $I_{\mathrm{Ca}}$ induced by changing dendrite area. By calculating $\mathrm{Q}_{\text {total }} / \mathrm{Q}_{\min }$ for each $\mathrm{AP}$, we show that the $\mathrm{Na}^{+}$entry ratio increases as firing rate is reduced (Figure 10C). This indicates that activating outward $I_{\mathrm{KAHP}}$ in the dendrite makes APs become inefficient to use $\mathrm{Na}^{+}$entry to generate their depolarization, thus reducing their metabolic efficiency.

We examine the ionic currents underlying the recorded spike trains with $p=0.4$ (Figure 11A). We find that the intensity of outward $I_{\mathrm{KAHP}}$ during each $\mathrm{AP}$ is much lower compared to $I_{\mathrm{Na}}$, $I_{\mathrm{K}}$, or $I_{\mathrm{SD}}$, even when it is sufficiently activated (Figure 11B). But activating such inhibitory current in dendritic chamber facilitates the hyperpolarization of its membrane voltage and results in slight increase in the outward level of internal current $I_{\mathrm{SD}}$ (Figures 11B,C). Then, the overlap between outward $I_{\mathrm{SD}}$ and $\mathrm{Na}^{+}$influx during an AP becomes progressively more prominent as $I_{\mathrm{KAHP}}$ is activated. The augment in their temporal overlap leads corresponding AP to import more $\mathrm{Na}^{+}$ions for achieving somatic depolarization (Figure 10A), which adds an additional metabolic cost. In this case, more of $\mathrm{Na}^{+}$influx is employed to compete with outward $I_{\mathrm{SD}}$, which effectively increases the excess $\mathrm{Na}^{+}$entry ratio (Figure 10C). Thus, activating outward $I_{\mathrm{KAHP}}$ in the dendrites reduces the efficient use of $\mathrm{Na}^{+}$entry and makes APs metabolically inefficient.

Moreover, the effects of adaptation currents on APs have been shown to be dependent on current stimulus (Prescott et al., 2006; Prescott and Sejnowski, 2008; Benda et al., 2010; Yi et al., 2015b). Here we use model III neuron to simulate how the metabolic efficiency of APs depends on the activation of $I_{\mathrm{KAHP}}$ as dendritic input is varied. We measure height and half-width, total and minimal $\mathrm{Na}^{+}$load, and $\mathrm{Na}^{+}$entry ratio for simulated APs. It is found that increasing dendritic input makes $I_{\mathrm{KAHP}}$ stronger and extends its activation procedure (Figure 12A, center). Then, activating outward $I_{\mathrm{KAHP}}$ with strong $I_{\mathrm{D}}$ produces larger effects on AP height and half-width (Figure 12B), total $\mathrm{Na}^{+}$load and minimal $\mathrm{Na}^{+}$load per spike (Figure 12C), as well as excess $\mathrm{Na}^{+}$entry ratio (Figure 12D). Even so, these items show similar trends with the activation of $I_{\text {KAHP. In particular, our }}$ predictions are reproducible in the cases of different dendritic inputs. That is, activating inhibitory $I_{\mathrm{KAHP}}$ in dendritic chamber increases both energy cost (Figure 12C, top) and $\mathrm{Na}^{+}$entry ratio (Figure 12D) per spike, which makes relevant AP metabolically inefficient. Note that applying strong $I_{\mathrm{D}}$ to dendritic chamber simultaneously increases the intensity of inward $I_{\mathrm{Ca}}$, especially during the initial APs after the onset of injection. Since outward $I_{\mathrm{KAHP}}$ is relatively weak in this phase, $I_{\mathrm{Ca}}$ dominates the outcome of their competition, which results in the marked decrease in AP shape, total $\mathrm{Na}^{+}$load, minimal $\mathrm{Na}^{+}$load and $\mathrm{Na}^{+}$entry ratio. After that, $I_{\mathrm{Ca}}$ decays and then the activated $I_{\mathrm{KAHP}}$ dominates the outcome of their competition, which results in SFA. Thus, we neglect the decrease in each item when we examine the effects of activating $I_{\text {KAHP }}$ on AP efficiency with different stimulus.

\section{DISCUSSION}

Our simulations develop three two-compartment biophysical models to describe the intrinsic properties of the dendrites and reproduce the APs initiated in cortical pyramidal cells. The relationships between the dendritic properties, the energy efficiency of APs, and the currents underlying relevant AP are determined. The excess $\mathrm{Na}^{+}$entry ratio is applied to quantify the 


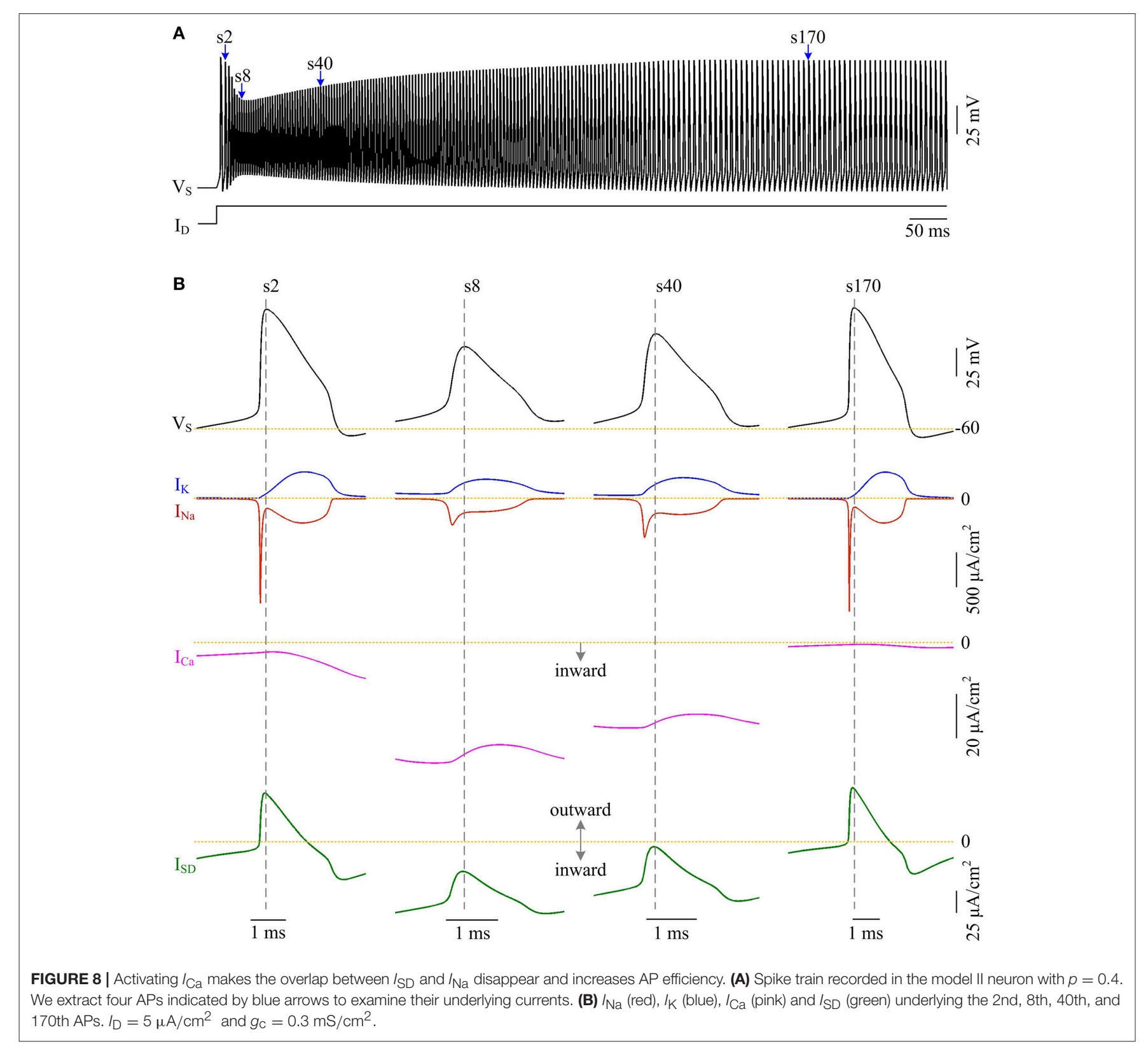

efficiency with which $\mathrm{Na}^{+}$influx is used for AP formation. These calculations allow us to identify how passive and active properties of the dendrites modulate AP efficiency in each model.

Our approach is to forward engineer simple point-neuron models to better understand how the passive and active dendrites affect the energy efficiency of somatic/axonal APs. We create the models only as complicated as required to reproduce the phenomena of interest. Note that the morphology and biophysics of real dendrites is extremely complicated and particular to specific cells. Creating a high-dimensional biophysical model to capture these non-linearities is reasonably straightforward. However, it may fail to provide a deeper insight than the physiological experiments upon which is based. In our forward engineered models, we exclude the extraneous details of pyramidal cells and reduce the number of core parameters to workable proportions. Such reduced point-neuron models allow us to simulate the core process of interest and gain a greater understanding of fundamental principles than biophysically realistic, extensive models.

We first examine the effects of two passive properties with our biophysical models. One relevant parameter is the ratio of dendrite area to total membrane area, and the other one is the internal coupling conductance connecting chambers. By systematically varying them within the model, we find that increasing dendrite area or coupling conductance both result in a marked increase in the internal current flowing between two chambers. This is an outward current flowing out of the soma, which overlaps with $\mathrm{Na}^{+}$influx during the upstroke of 
A model III: introducing $\mathrm{I}_{\mathrm{Ca}}$ and $\mathrm{I}_{\mathrm{KAHP}}$ to the dendrite of model I to induce spike-frequency adaptation

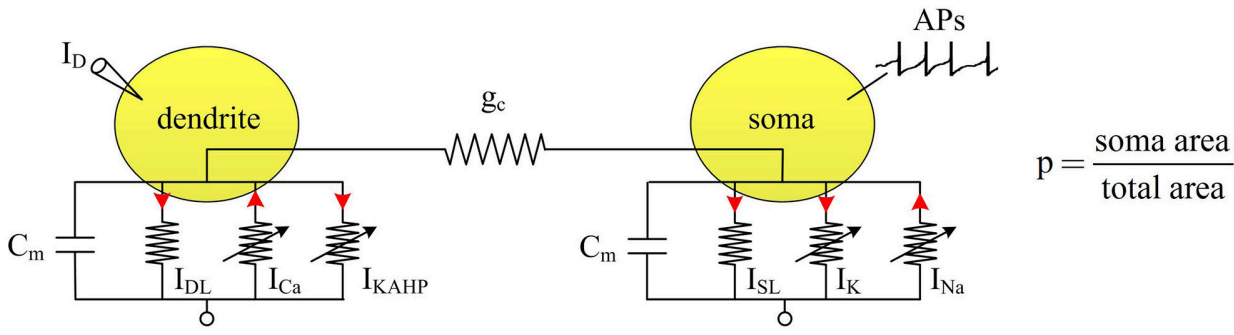

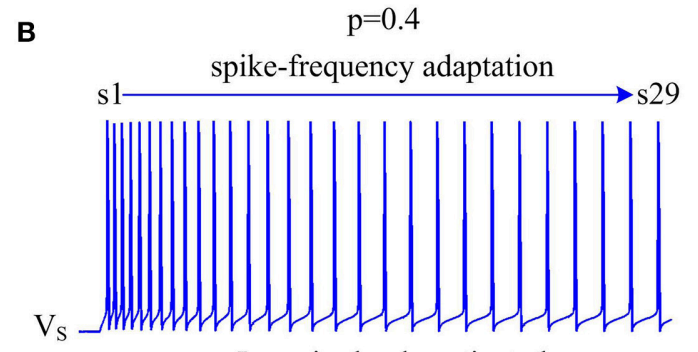

$\mathrm{I}_{\mathrm{KAHP}}$ is slowly activated
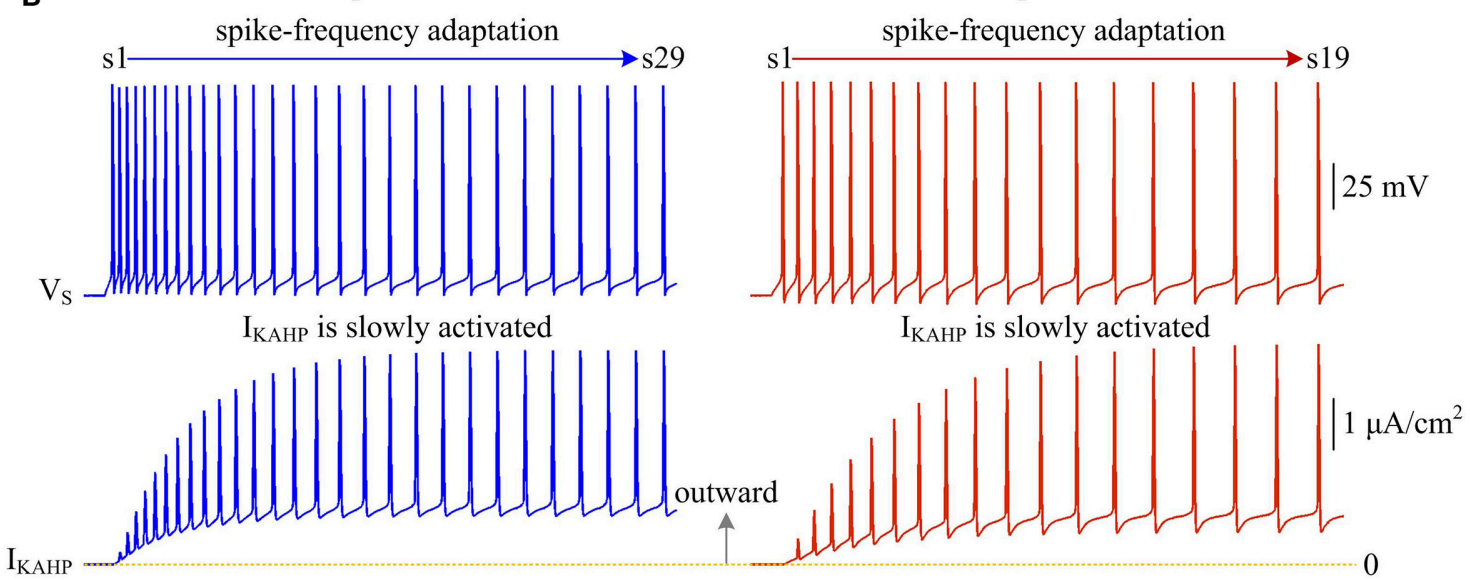

$\mathrm{I}_{\mathrm{KAHP}}$ is slowly activated
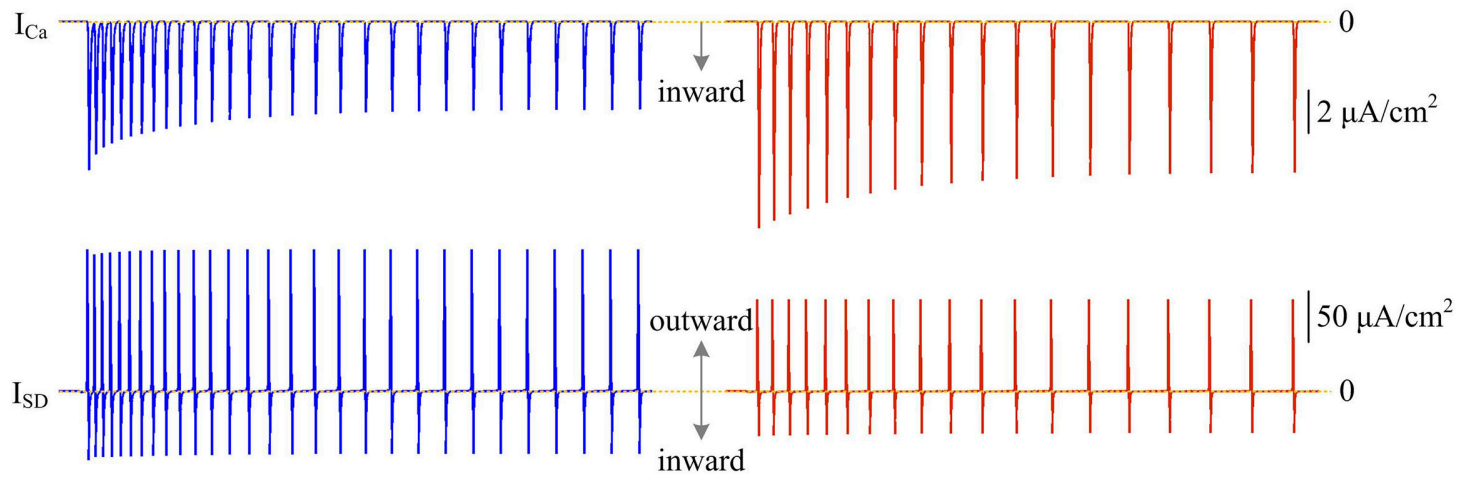

$\mathrm{I}_{\mathrm{D}}$

C

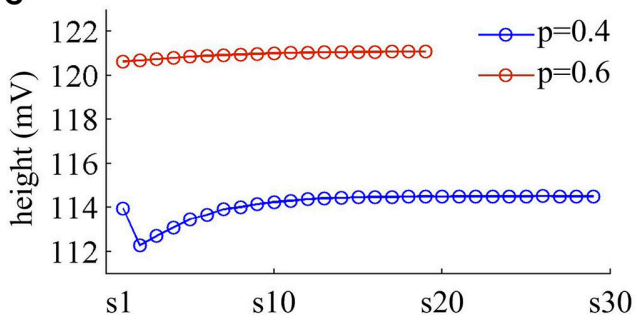

$100 \mathrm{~ms}$

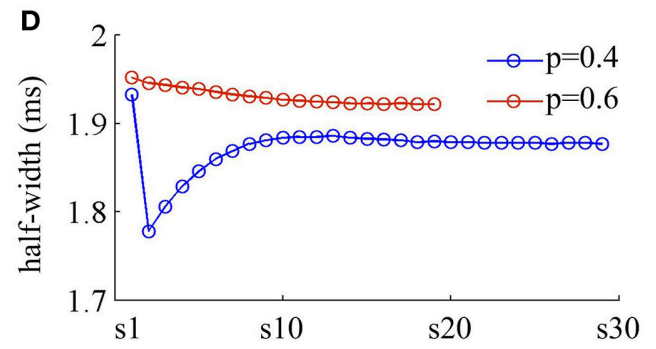

FIGURE 9 | Activating /KAHP in dendritic chamber results in SFA in model III. (A) Schematic of model III. An inward $\mathrm{Ca}^{2+}$ current $/ \mathrm{Ca}$ and a Ca ${ }^{2+}$-activated outward $\mathrm{K}^{+}$current $I_{\mathrm{KAHP}}$ are introduced to the dendritic chamber of model I. (B) Sample responses recorded in the soma with $p=0.4$ and 0.6 . $V_{\mathrm{S}}, I_{\mathrm{KAHP}}, I_{\mathrm{Ca}}$, and $I_{\mathrm{SD}}$ are plotted against time. With $p=0.4$ (left), there are 29 APs generated during the interval of 1,000 ms, and we number them s1 through s29 from left to right. With $p=$ 0.6 (right), there are 19 APs during the interval of $1,000 \mathrm{~ms}$, and we number them $\mathrm{s} 1$ through $\mathrm{s} 19$ from left to right. As $/$ KAHP is activated, the firing rate decays down to a lower steady-state level, and model III neuron generates SFA. (C) The height of each AP with $p=0.4$ and 0.6. (D) The half-width of each AP with $p=0.4$ and 0.6. $I_{\mathrm{D}}=2 \mu \mathrm{A} / \mathrm{cm}^{2}$ and $g_{\mathrm{C}}=0.6 \mathrm{mS} / \mathrm{cm}^{2}$. 

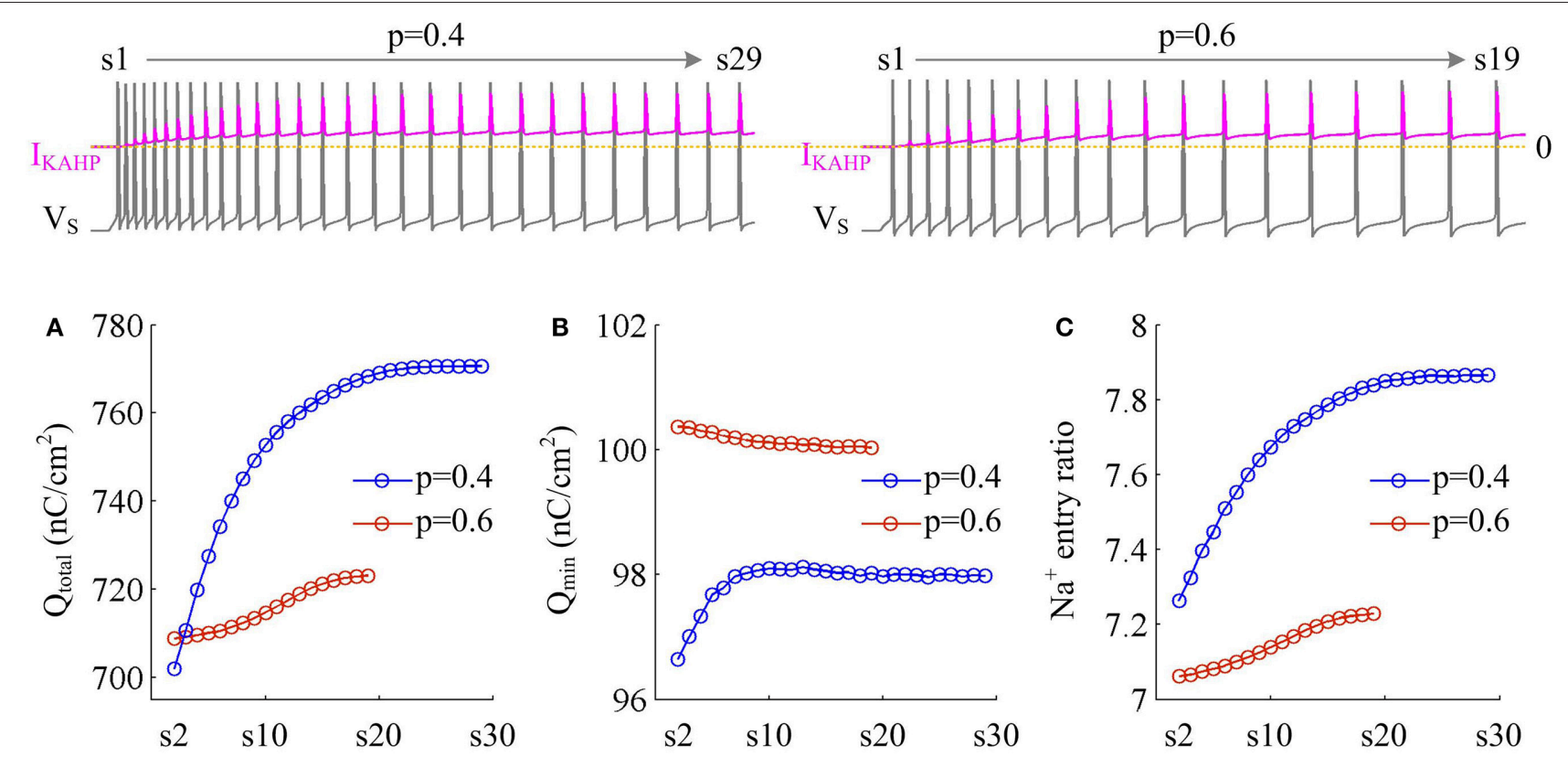

FIGURE 10 | Metabolic efficiency of the AP is reduced as $I_{K A H P}$ is activated. (A) Total $\mathrm{Na}^{+}$load $\mathrm{Q}_{\text {total }}$, (B) minimal $\mathrm{Na}^{+}$load $\mathrm{Q}_{\mathrm{min}}$, and (C) $\mathrm{Na}^{+}$entry ratio are respectively calculated for each AP during the activation of $I_{K A H P}$ with $p=0.4$ and 0.6. Top panels show the response of $V_{S}$ (gray) and $I_{K A H P}$ (pink) recorded in the model III with each value of $p$. Note that our examination starts from the $2 \mathrm{nd} \mathrm{AP}$, since $/ \mathrm{KAHP}$ is totally unactivated during the $1 \mathrm{st} A \mathrm{P}$. ID $=2 \mu \mathrm{A} / \mathrm{cm}{ }^{2}$ and $g_{\mathrm{c}}=0.6 \mathrm{mS} / \mathrm{cm}^{2}$.

the AP. Increasing the intensity of such inhibitory current makes the overlap more significant. Then, the $\mathrm{Na}^{+}$entry efficiency of relevant AP is reduced. It has been shown that the voltage-gated channels or pumps must fit into a limited membrane area (Faisal et al., 2005). With single-compartment models, Sengupta et al. (2013) demonstrate that membrane area constrains the available channels used for the information coding, the signaling rate and the energy efficiency of the cell. By simulating two-compartment models, we predict that the membrane area of either soma or dendrite is a determinant of AP efficiency, which is comparable to their study.

We also simulate the metabolic efficiency of APs associated with active dendrites. Two types of dendritic channels are examined. One is inward $\mathrm{Ca}^{2+}$ current $I_{\mathrm{Ca}}$, and the other one is outward $\mathrm{Ca}^{2+}$-dependent $\mathrm{K}^{+}$current $I_{\mathrm{KAHP}}$. Their activations both occur at slower timescales than the fast dynamics of spike initiation, which allows us to observe how they modulate AP efficiency in a recorded spike train. Our simulations show that activating active current in dendrites can either enhance or reduce the excess $\mathrm{Na}^{+}$entry ratio of somatic AP, depending on whether it is depolarizing (inward) or hyperpolarizing (outward). The activation of inward $I_{\mathrm{Ca}}$ results in a local depolarization in dendritic chamber and evokes dendritic spike. Such event effectively decreases the outward level of internal current $I_{\mathrm{SD}}$ and controls it to flow into the soma. In this case, internal current $I_{\mathrm{SD}}$ is not to overlap and compete with $\mathrm{Na}^{+}$influx but to cooperate with it to depolarize somatic membrane, thus increasing AP efficiency. On the contrary, activating $I_{\mathrm{KAHP}}$ hyperpolarizes dendritic membrane and increases the outward level of $I_{\mathrm{SD}}$. Such event results in more overlap of inhibitory $I_{\mathrm{SD}}$ and $\mathrm{Na}^{+}$influx, thus decreasing AP efficiency.

The existence of inward active currents (including $\mathrm{Na}^{+}$, NMDA and $\mathrm{Ca}^{2+}$ ) in dendrites endows them with powerful ability of synaptic integration (Spruston, 2008; Major et al., 2013; Stuart and Spruston, 2015; Tran-Van-Minh et al., 2015). Particularly, the dendritic spike arising from their activation completely alters the relative importance of synaptic inputs (Larkum et al., 2001, 2004), which lies at the heart of cortical computation (Major et al., 2013; Stuart and Spruston, 2015; Tran-Van-Minh et al., 2015). In vitro experiments have observed that dendritic $\mathrm{Ca}^{2+}$ spike triggers a burst of APs in the soma/axon and switches the firing mode of the cell to bursting (Williams and Stuart, 1999; Larkum and Zhu, 2002; Larkum et al., 2004; Palmer et al., 2012; Larkum, 2013). With a two-compartment model, our earlier study (Yi et al., 2017) has successfully reproduced this observation and explained how dendritic spike participates in somatic AP initiation. In present study, we show that the activation of $\mathrm{Ca}^{2+}$ current in apical dendrites makes $\mathrm{Na}^{+}$entry become efficiently used by APs for their depolarization, thus facilitating the effective utilization of metabolic energy. Our simulations suggest that the supralinear integration operated by dendritic $\mathrm{Ca}^{2+}$ spike is a contributory factor for the metabolically efficient coding by cortical pyramidal cells. Note that we only consider slow $\mathrm{Ca}^{2+}$ current in our simulations. The effects of other active channels, such as NMDA or $\mathrm{Na}^{+}$, need to be examined in future work. 


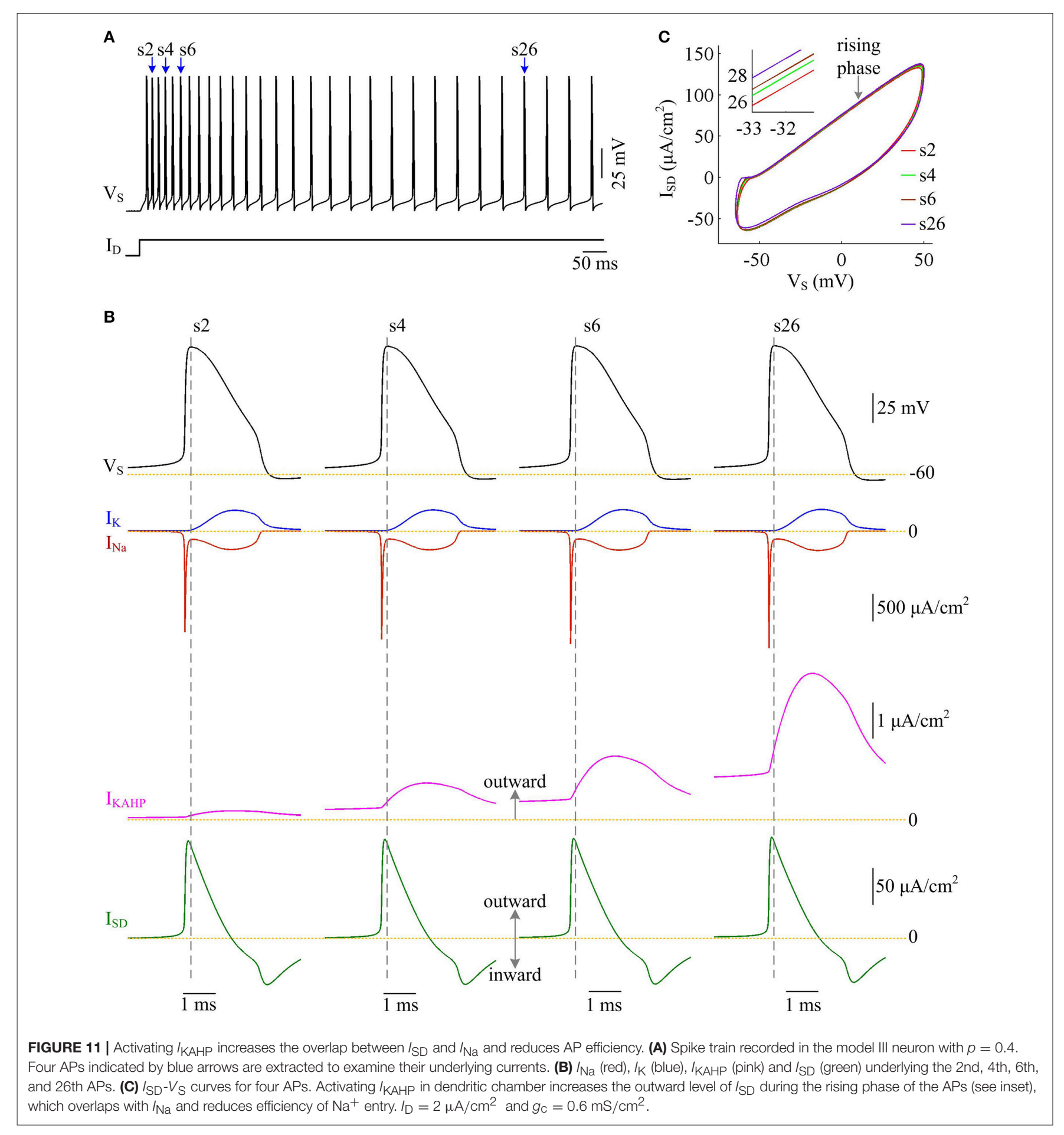

Outward $I_{\mathrm{KAHP}}$ in dendritic sites is an ionic mechanism for causing SFA. In fact, the $I_{\mathrm{KAHP}}$ in soma/axon can also lead the cell to adapt its spike frequency (Benda et al., 2010). Similarly, other inhibitory currents, including voltage-gated $\mathrm{K}^{+}$current $I_{\mathrm{M}}$ (Brown and Adams, 1980) and $\mathrm{Na}^{+}$-activated $\mathrm{K}^{+}$current $I_{\mathrm{KNa}}$ (Wang et al., 2003), are also potential mechanisms for inducing SFA on slow timescales. With single-compartment models, our earlier study (Yi et al., 2016a) has showed that activating $I_{M}$ or $I_{\mathrm{KAHP}}$ in soma/axon directly leads to the overlap between with $\mathrm{Na}^{+}$influx during the depolarizing phase of AP, effectively increasing the $\mathrm{Na}^{+}$load to achieve depolarization, and thus resulting in an inefficient AP with higher energy consumption. Our present study finds that the activation of $I_{\text {KAHP }}$ in dendritic chamber takes effects in a different way. It directly increases the 

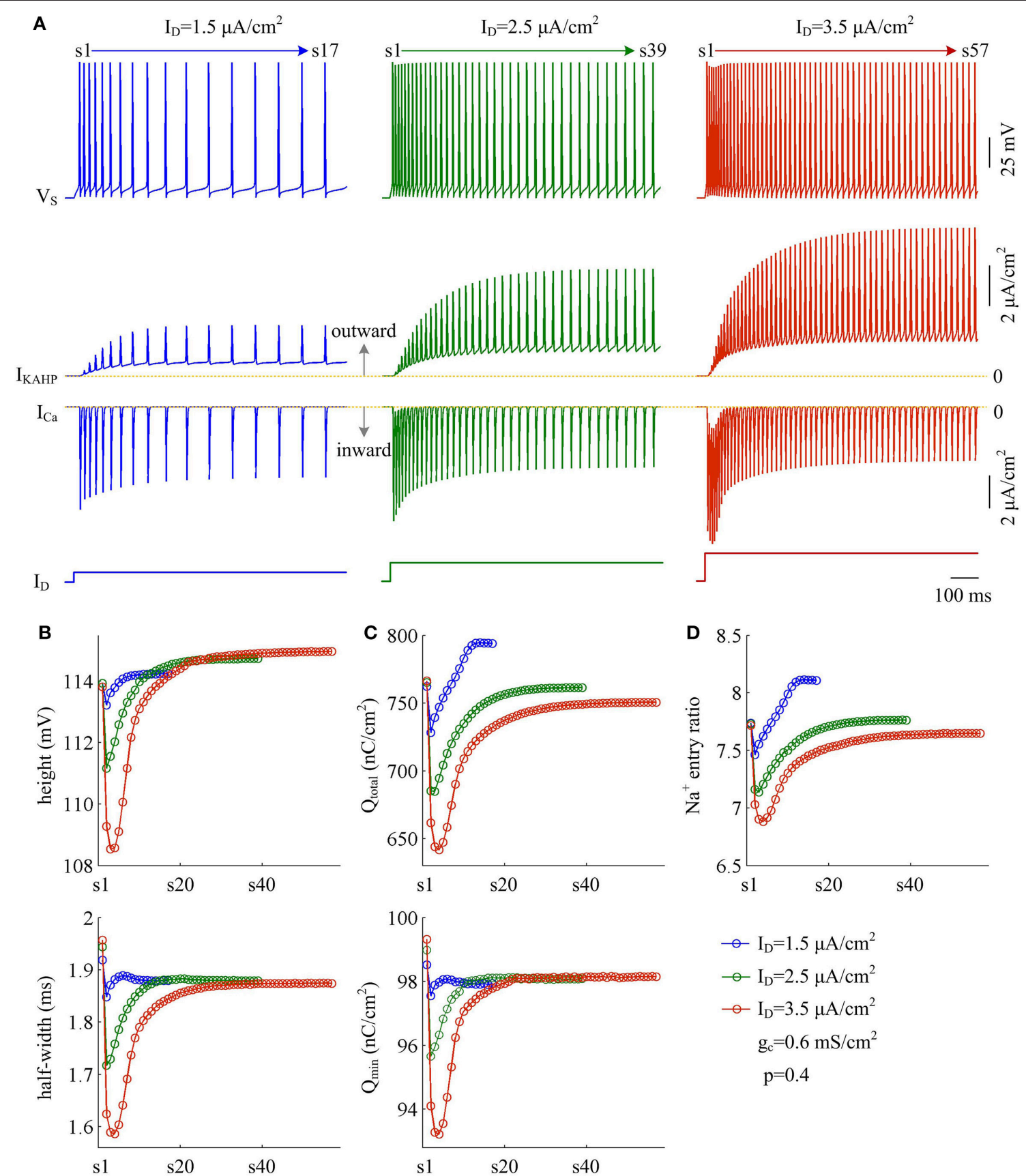

$$
\begin{aligned}
-\mathrm{I}_{\mathrm{D}} & =1.5 \mu \mathrm{A} / \mathrm{cm}^{2} \\
-\mathrm{I}_{\mathrm{D}} & =2.5 \mu \mathrm{A} / \mathrm{cm}^{2} \\
-\mathrm{I}_{\mathrm{D}} & =3.5 \mu \mathrm{A} / \mathrm{cm}^{2} \\
\mathrm{~g}_{\mathrm{c}} & =0.6 \mathrm{mS} / \mathrm{cm}^{2} \\
\mathrm{p} & =0.4
\end{aligned}
$$

FIGURE 12 | Activation of $I_{K A H P}$ by strong dendritic input results in inefficient APs. (A) Sample responses of the model III neuron evoked by $I_{D}=1.5 \mu A / \mathrm{cm}^{2}$, $2.5 \mu \mathrm{A} / \mathrm{cm}^{2}$, and $3.5 \mu \mathrm{A} / \mathrm{cm}^{2} . V_{\mathrm{S}}, I_{\mathrm{KAHP}}$, and $I_{\mathrm{Ca}}$ are plotted against time. During the interval of 1000 ms, model III neuron respectively generates 17,39 , and 57 APs. (B) The height (top) and half-width (bottom) of each AP with three values of $I_{D}$. (C) Total $\mathrm{Na}^{+}$load $\mathrm{Q}_{\text {total }}$ (top) and minimal $\mathrm{Na}^{+}$load $\mathrm{Q}_{\mathrm{min}}$ (bottom) of each AP. (D) Excess $\mathrm{Na}^{+}$entry ratio of each AP. Note that three intensities of $I_{\mathrm{D}}$ are all below the threshold for activating $I_{\mathrm{Ca}}$ to trigger dendritic Ca ${ }^{2+}$ spike. Once $I_{\mathrm{D}}$ reaches that threshold, the activated $I_{\mathrm{Ca}}$ dominates the outputs of model III neuron, and the SFA will disappear. $p=0.4$ and $g_{\mathrm{c}}=0.6 \mathrm{mS} / \mathrm{cm}^{2}$.

outward level of internal current $I_{\mathrm{SD}}$, which overlaps with $\mathrm{Na}^{+}$ influx in the soma and reduces AP efficiency. Even so, the similar outcomes of their activation indicate that the presence of slow inhibitory currents in dendrites, soma or axon makes an AP less efficiently use $\mathrm{Na}^{+}$entry for its depolarization. Note that SFA is a common strategy used by neurons to encode signals, which is ubiquitous in the central nervous system (Sharpee et al., 2006; Wark et al., 2007). It has been shown to effectively improve neural computation (Benda et al., 2005, 2010; Sharpee et al., 2006; Wark et al., 2007; Peron and Gabbiani, 2009). In this sense, the 
ionic currents inducing SFA should be contributory factors for enhancing the metabolic efficiency of information coding. Their relationship needs further investigation in following works.

Two-compartment model is the minimal neuronal unit for capturing the interaction between dendrites and soma/axon, which has been widely used to describe the input-output transfer of single pyramidal cell. In particular, our earlier studies (Yi et al., 2014a,b, 2015b, 2016b, 2017) have demonstrated that dendrite area, dendritic spike and coupling conductance all play crucial roles in determining the transfer function of two-compartment model neurons. For example, they could alter the dynamic basis of spike initiation (Yi et al., 2014a, 2017), the outcome of subthreshold competition between opposite currents (Yi et al., 2014a,b, 2015b), the dynamics of AP threshold (Yi et al., 2016b), the electric field threshold for triggering spikes (Yi et al., 2014b), and the field-induced SFA (Yi et al., 2015b). In current study, we find that the effects of them on internal current flowing between chambers are also translated into distinct modulation of AP efficiency. These simulations demonstrate that such kind of point-neuron models is an effective tool for predicting how passive and active dendrites participate in simple neural computation. Their predictive power will hopefully result in increased applications of these models within relevant fields.

Experimental and computational approaches have been used to determine the energy efficiency of APs. A major determinant of AP efficiency is the overlap of inward and outward currents (Sengupta et al., 2010; Niven, 2016), which is highly variable between neurons. Some contributory factors have been identified, including conductance magnitudes of $\mathrm{Na}^{+}$or $\mathrm{K}^{+}$(Hasenstaub et al., 2010; Sengupta et al., 2010), kinetics of their activation and inactivation (Crotty and Levy, 2007; Hasenstaub et al., 2010; Sengupta et al., 2010; Moujahid and d'Anjou, 2012; Yi et al., 2016a), temperature (Moujahid and d'Anjou, 2012; Yu et al., 2012), membrane capacitances (Crotty and Levy, 2007; Sengupta et al., 2010), AP shape (Carter and Bean, 2009), spike threshold dynamics (Yi et al., 2015a), and cell size (Sengupta et al., 2013). All of them are shown to alter the overlap between inward $\mathrm{Na}^{+}$ and outward $\mathrm{K}^{+}$currents to determine AP efficiency. For a specific cell, AP efficiency also varies across different parts (Alle et al., 2009; Schmidt-Hieber and Bischofberger, 2010). Axonal APs exhibit relatively little overlap in $\mathrm{Na}^{+}$and $\mathrm{K}^{+}$currents than soma, resulting in higher efficiency. Such difference is largely owing to the prevalent Kv1.1/1.2 channels (Kole et al., 2007; Shu et al., 2007) and faster $\mathrm{Na}^{+}$kinetics (Schmidt-Hieber and Bischofberger, 2010) in the AIS. Unlike these studies, we predict that the passive properties and active channels in the dendrites cause the variability in AP efficiency by altering the overlap between inward $\mathrm{Na}^{+}$and outward internal current. Thus, the dendrites not only have marked and strong impacts on the final output of neuronal computation, which also affect the energy consumption and efficiency of somatic/axonal APs.

In our simulations, there is significant overlap between inward $\mathrm{Na}^{+}$and outward $\mathrm{K}^{+}$currents during the APs. It arises from the simultaneous activation of two active currents. Under this condition, $\mathrm{Na}^{+}$enters the cell at the same time that $\mathrm{K}^{+}$exits the cell. These fluxes mostly cancel each other, which increase total $\mathrm{Na}^{+}$entry needed to formulate the APs. Such temporal overlap occurs during the repolarization of the AP. Except for delayed rectifier $\mathrm{K}^{+}, I_{\mathrm{SD}}$ is another current flowing out of the soma in our two-compartment models. This internal current mainly appears during the upstroke of APs, which effectively leads to unnecessary $\mathrm{Na}^{+}$influx. The passive and active dendrites participate in somatic APs through controlling the $I_{\mathrm{SD}}$. Calculating the overlap $\mathrm{Na}^{+}$load during the repolarization is unable to measure how outward $I_{\mathrm{SD}}$ overlaps with $\mathrm{Na}^{+}$influx. Instead, we quantify total $\mathrm{Na}^{+}$entry during the AP relative to the minimal charge necessary for its depolarization. The $\mathrm{Na}^{+}$entry ratio calculated in this way effectively measures how efficiently an AP uses $\mathrm{Na}^{+}$influx to produce its depolarization, which takes the temporal overlap of $I_{\mathrm{SD}}$ and $I_{\mathrm{Na}}$ into consideration. In fact, both overlap $\mathrm{Na}^{+}$load and $\mathrm{Na}^{+}$entry ratio are effective measures for determining the potential biophysical causes for the variability in metabolic efficiency of APs among neurons. Based on our simulations, we suggest using $\mathrm{Na}^{+}$entry ratio to measure the AP efficiency when there are outward currents in its depolarizing phase.

Experiments have recorded a myriad of APs with a wide variety of shapes (height and width). An earlier study by Carter and Bean (2009) has suggested that the variability in $\mathrm{Na}^{+}$ entry efficiency among neurons primarily arises from different AP shapes rather than $\mathrm{Na}^{+}$channel kinetics. But Sengupta et al. (2010) then showed that AP height and width are poor predictors of energy consumption. Instead, the biophysical properties of ionic channels could be perfectly matched to reduce the overlap between inward and outward currents to minimize the ATP cost of the APs. Similarly, Yu et al. (2012) reported that the changes in AP shape do not explain the modulations of metabolic efficiency of APs with temperature. In our simulations, we find that the passive and active dendrites affect both the shape of APs and the overlap between their opposite currents, thus altering the metabolic cost of somatic APs. Using either $\mathrm{Na}^{+}$entry ratio or AP shape alone is unable to explain the effects of dendritic properties on AP efficiency. This is comparable to the prediction of Sengupta et al. (2010) and Yu et al. (2012). By taking two factors into consideration, our study indicates that the biophysical properties and morphologies of the dendrites are potential causes for altering AP shape and the overlap between inward and outward currents, thus predicting the variable AP efficiency among pyramidal cells.

There are some limitations in our model and technical considerations. First, our simulations only examine the effects of varying one core parameter. Future work should focus on how their possible combinations affect and maximize AP efficiency in pyramidal cells. Second, the morphology and active channels in the dendrites are very complicated for a real cell. Including them in the biophysically-based models to describe their relationships with AP efficiency will surely facilitate our interpretation of the energy expenditure of neuronal computation. Finally, the present study only focuses on the energy efficiency of single AP and not formally simulates the information coding by relevant model neurons. How passive and active dendrites participate in information transmission and then affect its energy efficiency should be examined in following works. 


\section{CONCLUSION}

With biophysical models, we have obtained basic principles about how passive and active dendrites affect the $\mathrm{Na}^{+}$entry efficiency of somatic/axonal APs. Our results emphasize that they are all potential factors for the variability in AP efficiency between pyramidal neurons. By relating dendritic properties to the overlap between $\mathrm{Na}^{+}$influx and internal current, we provide an interpretable insight into their effects. Determining their contributions to the AP efficiency is a first but necessary step toward a mechanistic understanding of how single cell consumes metabolic energy to perform computation. Our models and predictions can be used to examine how other biophysics and morphologies of the dendrites affect spike efficiency. Such examinations are essential for deeply interpreting how these

\section{REFERENCES}

Alle, H., Roth, A., and Geiger, J. R. P. (2009). Energy-efficient action potentials in hippocampal mossy fibers. Science 325, 1405-1408. doi: $10.1126 /$ science. 1174331

Attwell, D., and Gibb, A. (2005). Neuroenergetics and the kinetic design of excitatory synapses. Nat. Rev. Neurosci. 6, 841-849. doi: 10.1038/nrn1784

Attwell, D., and Laughlin, S. B. (2001). An energy budget for signaling in the grey matter of the brain. J. Cereb. Blood Flow Metab. 21, 1133-1145. doi: 10.1097/00004647-200110000-00001

Benda, J., Longtin, A., and Maler, L. (2005). Spike-frequency adaptation separates transient communication signals from background oscillations. J. Neurosci. 25, 2312-2321. doi: 10.1523/JNEUROSCI.4795-04.2005

Benda, J., Maler, L., and Longtin, A. (2010). Linear versus nonlinear signal transmission in neuron models with adaptation currents or dynamic thresholds. J. Neurophysiol. 104, 2806-2820. doi: 10.1152/jn.00240.2010

Branco, T., and Häusser, M. (2010). The single dendritic branch as a fundamental functional unit in the nervous system. Curr. Opin. Neurobiol. 20, 494-502. doi: 10.1016/j.conb.2010.07.009

Brown, D. A., and Adams, P. R. (1980). Muscarinic suppression of a novel voltage-sensitive $\mathrm{K}^{+}$current in a vertebrate neurone. Nature 283, 673-676. doi: $10.1038 / 283673 \mathrm{a} 0$

Carter, B. C., and Bean, B. P. (2009). Sodium entry during action potentials of mammalian neurons: incomplete inactivation and reduced metabolic efficiency in fast-spiking neurons. Neuron 64, 898-909. doi: 10.1016/j.neuron.2009.12.011

Crotty, P., and Levy, W. B. (2007). Effects of $\mathrm{Na}^{+}$channel inactivation kinetics on metabolic energy costs of action potentials. Neurocomputing 70, 1652-1656. doi: 10.1016/j.neucom.2006.10.063

Crotty, P., Sangrey, T., and Levy, W. B. (2006). Metabolic energy cost of action potential velocity. J. Neurophysiol. 96, 1237-1246. doi: 10.1152/jn.01204.2005

Diaz, F., Garcia, S., and Moraes, C. T. (2012). Metabolic adaptations in neurons with complex IV deficiency. Mitochondrion 12:585. doi: 10.1016/j.mito.2012.07.089

Engl, E., and Attwell, D. (2015). Non-signalling energy use in the brain. J. Physiol. 593, 3417-3429. doi: 10.1113/jphysiol.2014.282517

Faisal, A. A., White, J. A., and Laughlin, S. B. (2005). Ion-channel noise places limits on the miniaturization of the brain's wiring. Curr. Biol. 15, 1143-1149. doi: 10.1016/j.cub.2005.05.056

Grienberger, C., Chen, X., and Konnerth, A. (2015). Dendritic function in vivo. Trends Neurosci. 38, 45-54. doi: 10.1016/j.tins.2014.11.002

Hasenstaub, A., Otte, S., Callaway, E., and Sejnowski, T. J. (2010). Metabolic cost as a unifying principle governing neuronal biophysics. Proc. Natl. Acad. Sci. U.S.A. 107, 12329-12334. doi: 10.1073/pnas.0914886107

Howarth, C., Gleeson, P., and Attwell, D. (2012). Updated energy budgets for neural computation in the neocortex and cerebellum. J. Cereb. Blood Flow Metab. 32, 1222-1232. doi: 10.1038/jcbfm.2012.35 subcellular processes participate in the information processing of neurons and neural circuits.

\section{AUTHOR CONTRIBUTIONS}

Conceived and designed the work: GY, JW, XW, BD. Performed the simulations: GY. Analyzed and interpreted the data: GY, JW. Wrote the paper: GY, JW, XW.

\section{ACKNOWLEDGMENTS}

This work was supported by grants from the National Natural Science Foundation of China (Nos. 61372010, 61471265, and 61601320), and the China Postdoctoral Science Foundation (No. 2017T100158).

Hu, H., Martina, M., and Jonas, P. (2010). Dendritic mechanisms underlying rapid synaptic activation of fast-spiking hippocampal interneurons. Science 327, 52-58. doi: 10.1126/science.1177876

Ju, H., Hines, M. L., and Yu, Y. (2016). Cable energy function of cortical axons. Sci. Rep. 6:29686. doi: 10.1038/srep29686

Kandel, E. R., Schwartz, J. H., Jessell, T. M., Siegelbaum, S. A., and Hudspeth, A. J. (2012). Principles of Neural Science. New York, NY: McGraw-Hill Medical.

Kole, M. H., Letzkus, J. J., and Stuart, G. J. (2007). Axon initial segment Kv1 channels control axonal action potential waveform and synaptic efficacy. Neuron 55, 633-647. doi: 10.1016/j.neuron.2007.07.031

Larkum, M. (2013). A cellular mechanism for cortical associations: an organizing principle for the cerebral cortex. Trends Neurosci. 36, 141-151. doi: 10.1016/j.tins.2012.11.006

Larkum, M. E., Senn, W., and Lüscher, H. R. (2004). Top-down dendritic input increases the gain of layer 5 pyramidal neurons. Cereb. Cortex 14, 1059-1070. doi: $10.1093 /$ cercor/bhh065

Larkum, M. E., and Zhu, J. J. (2002). Signaling of layer 1 and whisker evoked Ca2 ${ }^{+}$ and $\mathrm{Na}^{+}$action potentials in distal and terminal dendrites of rat neocortical pyramidal neurons in vitro and in vivo. J. Neurosci. 22, 6991-7005.

Larkum, M. E., Zhu, J. J., and Sakmann, B. (2001). Dendritic mechanisms underlying the coupling of the dendritic with the axonal action potential initiation zone of adult rat layer 5 pyramidal neurons. J. Physiol. 533, 447-466. doi: 10.1111/j.1469-7793.2001.0447a.x

Mainen, Z. F., and Sejnowski, T. J. (1996). Influence of dendritic structure on firing pattern in model neocortical neurons. Nature 382, 363-366. doi: $10.1038 / 382363 \mathrm{a} 0$

Major, G., Larkum, M. E., and Schiller, J. (2013). Active properties of neocortical pyramidal neuron dendrites. Annu. Rev. Neurosci. 36, 1-24. doi: 10.1146/annurev-neuro-062111-150343

Moujahid, A., and d'Anjou, A. (2012). Metabolic efficiency with fast spiking in the squid axon. Front. Comput. Neurosci. 6:95. doi: 10.3389/fncom.2012.00095

Niven, J. E. (2016). Neuronal energy consumption: biophysics, efficiency and evolution. Curr. Opin. Neurobiol. 41, 129-135. doi: 10.1016/j.conb.2016.09.004

Niven, J. E., and Laughlin, S. B. (2008). Energy limitation as a selective pressure on the evolution of sensory systems. J. Exp. Biol. 211, 1792-1804. doi: 10.1242/jeb.017574

Palmer, L. M., Schulz, J. M., Murphy, S. C., Ledergerber, D., Murayama, M., and Larkum, M. E. (2012). The cellular basis of GABA(B)mediated interhemispheric inhibition. Science 335, 989-993. doi: $10.1126 /$ science. 1217276

Park, E. H., Barreto, E., Gluckman, B. J., Schiff, S. J., and So, P. (2005). A model of the effects of applied electric fields on neuronal synchronization. J. Comput. Neurosci. 19, 53-70. doi: 10.1007/s10827-005-0214-5

Peron, S., and Gabbiani, F. (2009). Spike frequency adaptation mediates looming stimulus selectivity in a collision-detecting neuron. Nat. Neurosci. 12, 318-326. doi: $10.1038 / \mathrm{nn} .2259$ 
Pinsky, P. F., and Rinzel, J. (1994). Intrinsic and network rhythmogenesis in a reduced Traub model for CA3 neurons. J. Comput. Neurosci. 1, 39-60. doi: 10.1007/BF00962717

Prescott, S. A., De Koninck, Y., and Sejnowski, T. J. (2008). Biophysical basis for three distinct dynamical mechanisms of action potential initiation. PLoS Comput. Biol. 4:e1000198. doi: 10.1371/journal.pcbi.1000198

Prescott, S. A., Ratté, S., De Koninck, Y., and Sejnowski, T. J. (2006). Nonlinear interaction between shunting and adaptation controls a switch between integration and coincidence detection in pyramidal neurons. J. Neurosci. 26, 9084-9097. doi: 10.1523/JNEUROSCI.1388-06.2006

Prescott, S. A., and Sejnowski, T. J. (2008). Spike-rate coding and spike-time coding are affected oppositely by different adaptation mechanisms. J. Neurosci. 28, 13649-13661. doi: 10.1523/JNEUROSCI.1792-08.2008

Schmidt-Hieber, C., and Bischofberger, J. (2010). Fast sodium channel gating supports localized and efficient axonal action potential initiation. J. Neurosci. 30, 10233-10242. doi: 10.1523/JNEUROSCI.6335-09.2010

Schreiber, S., Machens, C. K., Herz, A. V., and Laughlin, S. B. (2002). Energyefficient coding with discrete stochastic events. Neural Comput. 14, 1323-1346. doi: 10.1162/089976602753712963

Schuchmann, S., Buchheim, K., Heinemann, U., Hosten, N., and Buttgereit, F. (2005). Oxygen consumption and mitochondrial membrane potential indicate developmental adaptation in energy metabolism of rat cortical neurons. Eur. J. Neurosci. 21, 2721-2732. doi: 10.1111/j.1460-9568.2005.04109.x

Sengupta, B., Faisal, A. A., Laughlin, S. B., and Niven, J. E. (2013). The effect of cell size and channel density on neuronal information encoding and energy efficiency. J. Cereb. Blood Flow Metab. 33, 1465-1473. doi: $10.1038 /$ jcbfm. 2013.103

Sengupta, B., Laughlin, S. B., and Niven, J. E. (2014). Consequences of converting graded to action potentials upon neural information coding and energy efficiency. PLoS Comput. Biol. 10:e1003439. doi: 10.1371/journal.pcbi.1003439

Sengupta, B., Stemmler, M., Laughlin, S. B., and Niven, J. E. (2010). Action potential energy efficiency varies among neuron types in vertebrates and invertebrates. PLoS Comput. Biol. 6:e1000840. doi: 10.1371/journal.pcbi.1000840

Sharpee, T. O., Sugihara, H., Kurgansky, A. V., Rebrik, S. P., Stryker, M. P., and Miller, K. D. (2006). Adaptive filtering enhances information transmission in visual cortex. Nature 439, 936-942. doi: 10.1038/nature04519

Shu, Y., Yu, Y., Yang, J., and McCormick, D. A. (2007). Selective control of cortical axonal spikes by a slowly inactivating $\mathrm{K}^{+}$current. Proc. Natl. Acad. Sci. U.S.A. 104, 11453-11458. doi: 10.1073/pnas.07020 41104

Spruston, N. (2008). Pyramidal neurons: dendritic structure and synaptic integration. Nat. Rev. Neurosci. 9, 206-221. doi: 10.1038/nrn2286

Stuart, G. J., and Spruston, N. (2015). Dendritic integration: 60 years of progress. Nat. Neurosci. 18, 1713-1721. doi: 10.1038/nn.4157

Stuart, G., Spruston, N., Sakmann, B., and Häusser, M. (1997). Action potential initiation and backpropagation in neurons of the mammalian CNS. Trends Neurosci. 20, 125-131. doi: 10.1016/S0166-2236(96)10075-8

Tran-Van-Minh, A., Cazé, R. D., Abrahamsson, T., Cathala, L., Gutkin, B. S., and DiGregorio1, D. A. (2015). Contribution of sublinear and supralinear dendritic integration to neuronal computations. Front. Cell. Neurosci. 9:67. doi: 10.3389/fncel.2015.00067

Wang, L. F., Jia, F., Liu, X. Z., Song, Y. L., and Yu, L. C. (2015). Temperature effects on information capacity and energy efficiency of HodgkinHuxley neuron. Chin. Phys. Lett. 32:108701. doi: 10.1088/0256-307X/32/10/1 08701
Wang, X. J. (1998). Calcium coding and adaptive temporal computation in cortical pyramidal neurons. J. Neurophysiol. 79, 1549-1566.

Wang, X. J., Liu, Y., Sanchez-Vives, M., and McCormick, D. (2003). Adaptation and temporal decorrelation by single neurons in the primary visual cortex. J. Neurophysiol. 89, 3279-3293. doi: 10.1152/jn.00242.2003

Wark, B., Lundstrom, B. N., and Fairhall, A. (2007). Sensory adaptation. Curr. Opin. Neurobiol. 17, 423-429. doi: 10.1016/j.conb.2007.07.001

Williams, S. R., and Stuart, G. J. (1999). Mechanisms and consequences of action potential burst firing in rat neocortical pyramidal neurons. J. Physiol. 521, 467-482. doi: 10.1111/j.1469-7793.1999.00467.x

Yi, G. S., Wang, J., Li, H. Y., Wei, X. L., and Deng, B. (2016a). Metabolic energy of action potentials modulated by spike frequency adaptation. Front. Neurosci. 10:534. doi: 10.3389/fnins.2016.00534

Yi, G. S., Wang, J., Tsang, K. M., Wei, X. L., and Deng, B. (2015a). Input-output relation and energy efficiency in the neuron with different spike threshold dynamics. Front. Comput. Neurosci. 9:62. doi: 10.3389/fncom.2015.00062

Yi, G. S., Wang, J., Tsang, K. M., Wei, X. L., Deng, B., and Han, C. X. (2015b). Spikefrequency adaptation of a two-compartment neuron modulated by extracellular electric fields. Biol. Cybern. 109, 287-306. doi: 10.1007/s00422-014-0642-2

Yi, G. S., Wang, J., Wei, X. L., and Deng, B. (2016b). Dynamics of spike threshold in a two-compartment neuron with passive dendrite. Commun. Nonlin. Sci. Numer. Simulat. 40, 100-111. doi: 10.1016/j.cnsns.2016.04.021

Yi, G. S., Wang, J., Wei, X. L., and Deng, B. (2017). Action potential initiation in a two-compartment model of pyramidal neuron mediated by dendritic $\mathrm{Ca}^{+}$ spike. Sci. Rep. 7:45684. doi: 10.1038/srep45684

Yi, G. S., Wang, J., Wei, X. L., Tsang, K. M., Chan, W. L., and Deng, B. (2014a). Neuronal spike initiation modulated by extracellular electric fields. PLoS ONE 9:e97481. doi: 10.1371/journal.pone.0097481

Yi, G. S., Wang, J., Wei, X. L., Tsang, K. M., Chan, W. L., Deng, B., et al. (2014b). Exploring how extracellular electric field modulates neuron activity through dynamical analysis of a two-compartment neuron model. J. Comput. Neurosci. 36, 383-399. doi: 10.1007/s10827-013-0479-z

Yu, L., and Liu, L. (2014). Optimal size of stochastic Hodgkin-Huxley neuronal systems for maximal energy efficiency in coding pulse signals. Phys. Rev. E 89:032725. doi: 10.1103/PhysRevE.89.032725

Yu, L., Zhang, C., Liu, L., and Yu, Y. (2016). Energy-efficient population coding constrains network size of a neuronal array system. Sci. Rep. 6:19369. doi: 10.1038/srep19369

Yu, Y., Hill, A. P., and McCormick, D. A. (2012). Warm body temperature facilitates energy efficient cortical action potentials. PLoS Comput. Biol. 8:e1002456. doi: 10.1371/journal.pcbi.1002456

Zhang, C., Liu, L. W., Wang, L. F., Yue, Y., and Yu, L. C. (2015). Optimal size for maximal energy efficiency in information processing of biological systems due to bistability. Chin. Phys. Lett. 32:110501. doi: 10.1088/0256-307X/32/11/110501

Conflict of Interest Statement: The authors declare that the research was conducted in the absence of any commercial or financial relationships that could be construed as a potential conflict of interest.

Copyright $(2017$ Yi, Wang, Wei and Deng. This is an open-access article distributed under the terms of the Creative Commons Attribution License (CC BY). The use, distribution or reproduction in other forums is permitted, provided the original author(s) or licensor are credited and that the original publication in this journal is cited, in accordance with accepted academic practice. No use, distribution or reproduction is permitted which does not comply with these terms. 